\title{
The transcription factor PRO44 and the histone chaperone ASF1 regulate distinct aspects of multicellular development in the filamentous fungus Sordaria macrospora
}

David Immanuel Schumacher ${ }^{1}$, Ramona Lütkenhaus ${ }^{1}$, Florian Altegoer ${ }^{1,2}$, Ines Teichert ${ }^{1}$, Ulrich Kück ${ }^{1}$ and Minou Nowrousian ${ }^{1 *}$ (D)

\begin{abstract}
Background: Fungal fruiting bodies are complex three-dimensional structures that are formed to protect and disperse the sexual spores. Their morphogenesis requires the concerted action of numerous genes; however, at the molecular level, the spatio-temporal sequence of events leading to the mature fruiting body is largely unknown. In previous studies, the transcription factor gene pro44 and the histone chaperone gene asf1 were shown to be essential for fruiting body formation in the ascomycete Sordaria macrospora. Both PRO44 and ASF1 are predicted to act on the regulation of gene expression in the nucleus, and mutants in both genes are blocked at the same stage of development. Thus, we hypothesized that PRO44 and ASF1 might be involved in similar aspects of transcriptional regulation. In this study, we characterized their roles in fruiting body development in more detail.

Results: The PRO44 protein forms homodimers, localizes to the nucleus, and is strongly expressed in the outer layers of the developing young fruiting body. Analysis of single and double mutants of asf 1 and three other chromatin modifier genes, cac2, crcl, and rtt106, showed that only asf1 is essential for fruiting body formation whereas cac2 and rtt106 might have redundant functions in this process. RNA-seq analysis revealed distinct roles for asf1 and pro44 in sexual development, with asf1 acting as a suppressor of weakly expressed genes during morphogenesis. This is most likely not due to global mislocalization of nucleosomes as micrococcal nuclease-sequencing did not reveal differences in nucleosome spacing and positioning around transcriptional start sites between $\triangle \mathrm{asf1}$ and the wild type. However, bisulfite sequencing revealed a decrease in DNA methylation in $\triangle$ asf1, which might be a reason for the observed changes in gene expression. Transcriptome analysis of gene expression in young fruiting bodies showed that pro44 is required for correct expression of genes involved in extracellular metabolism. Deletion of the putative transcription factor gene asm2, which is downregulated in young fruiting bodies of $\Delta$ pro44, results in defects during ascospore maturation.
\end{abstract}

Conclusions: In summary, the results indicate distinct roles for the transcription factor PRO44 and the histone chaperone ASF1 in the regulation of sexual development in fungi.

Keywords: Sordaria macrospora, Ascomycetes, Fruiting body development, Sexual development, Histone chaperone, Transcription factor, RNA-seq, Laser microdissection

\footnotetext{
* Correspondence: minou.nowrousian@rub.de

'Lehrstuhl für Allgemeine und Molekulare Botanik, Ruhr-Universität Bochum,

44780 Bochum, Germany

Full list of author information is available at the end of the article
}

(c) The Author(s). 2018 Open Access This article is distributed under the terms of the Creative Commons Attribution 4.0 International License (http://creativecommons.org/licenses/by/4.0/), which permits unrestricted use, distribution, and reproduction in any medium, provided you give appropriate credit to the original author(s) and the source, provide a link to the Creative Commons license, and indicate if changes were made. The Creative Commons Public Domain Dedication waiver (http://creativecommons.org/publicdomain/zero/1.0/) applies to the data made available in this article, unless otherwise stated. 


\section{Background}

Fungi are among several groups of eukaryotes that are able to develop complex multicellular structures [1-4]. One example for such structures are the fruiting bodies of filamentous ascomycetes (Pezizomycotina) [5-7]. Within fruiting bodies, sexual spores are formed, and the surrounding fruiting body structures can protect the spores and facilitate their distribution. Ascomycete fruiting bodies contain a number of cell types that are not found in vegetative mycelium [8-10]. The morphology of fruiting body development was studied in detail in the model organisms Neurospora crassa and Sordaria macrospora [8, 10]. In the homothallic (self-fertile) $S$. macrospora, fruiting body development is possible for a single strain without the need of a compatible mating partner. Sexual development starts with the formation of female sexual structures, the ascogonial coils, which are enveloped by sterile hyphae forming a young fruiting body called protoperithecium. The sterile, outer layers of the protoperithecium differentiate into a darkly pigmented outer layer and a less pigmented inner wall region, with additional cell types differentiating during the transition to a mature fruiting body (perithecium) [10]. The differentiation of fruiting bodies in fungi is accompanied by massive transcriptional changes that are thought to enable the differentiation of specific cell types $[6,11]$. At the molecular level, the regulatory principles that mediate correct spatio-temporal gene expression during fruiting body development are not clear yet. However, in recent years, a lot of progress has been made in identifying developmental genes that encode factors potentially influencing transcription; and this includes specific transcription factors as well as chromatin modifiers.

Well-studied transcription factor genes that are required for fruiting body development in a number of ascomycete species include, for example, several mating type genes $[12,13]$, genes encoding proteins of the velvet family [14], and homologs of the zinc cluster transcription factor PRO1 [15-20]. Another example of a conserved ascomycete transcription factor with a role in development is the GATA factor NsdD/SUB-1/PRO44 (from now on called PRO44 if not referring to a differently named specific ortholog). The corresponding gene was independently identified as affected in developmental mutants of Aspergillus nidulans (nsdD), Neurospora crassa (sub-1), and Sordaria macrospora (pro44) [17, 20, 21]. Furthermore, orthologs were shown to be essential for sexual development in Aspergillus fumigatus, Botrytis cinerea, and Trichoderma reesei [22-24]. These data indicate a conserved role for PRO44 in ascomycete fruiting body formation, as it is required for this process in evolutionary diverse species from the Sordariomycetes (N. crassa, $S$. macrospora, and $T$. reesei), Eurotiomycetes (A. nidulans and $A$. fumigatus), and Leotiomycetes (B. cinerea). In addition, the pro44 homolog from Pyronema confluens, a member of the early-diverging Pezizomycete lineage, can complement the developmental defects of an S. macrospora $\Delta$ pro44 mutant, suggesting a conserved molecular function that might have been already present in the last common ancestor of filamentous ascomycetes [25]. In addition to its role in sexual development, pro44 orthologs were shown to be involved in the regulation of light-dependent processes in $N$. crassa and B. cinerea [22, 26, 27]. For both species, transcriptome analyses identified genes that are differentially regulated in the absence of the transcription factor gene, and for $N$. crassa, ChIP (chromatin immunoprecipitation)-seq analyses identified direct genomic targets bound by the PRO44 ortholog SUB-1 [22, $26,27]$. However, these studies were performed with mycelia not grown under conditions for sexual development. Therefore the influence of pro44 orthologs on gene expression during fruiting body formation remains unknown. Previous studies in S. macrospora have shown that pro44 itself is strongly expressed in young fruiting bodies at the level of transcription, and that this expression is dependent on the transcription factor gene pro1 [28]. Therefore, one aim of this study was to determine the transcriptome of the $S$. macrospora $\Delta$ pro44 mutant in developing fruiting bodies, and to compare this with transcriptomes of other developmental mutants and the wild type at the same developmental stages to characterize the role of pro44 in potential regulatory networks. Specifically, we aimed to address the question whether there might be an overlap between the function of transcription factors like PRO44 and chromatin modifiers in fruiting body development.

For chromatin modifiers, little is known with respect to their role in fruiting body development. In general, chromatin modifiers can mediate changes of the DNA itself, e.g. through methylation, changes in nucleosome positioning, incorporation of histone variants, or numerous histone modifications [29-32]. In recent years, several genes with potential functions in chromatin modification were found to be involved in fruiting body morphogenesis, pointing to an important role for regulatory events at chromatin level in this process [33-36]. One such factor is the histone chaperone ASF1 that was identified as a developmental gene in S. macrospora [37]. Histone chaperones are a heterogeneous group of proteins that can be characterized by their ability to bind non-nucleosomal histones in vivo, and mediate the assembly of nucleosomes on DNA in vitro [38]. They are involved in all chromatin-dependent processes, e.g. DNA replication, repair, and transcription [39]. ASF1 is a conserved histone chaperone specific for histones $\mathrm{H} 3$ and H4 [40]. Interestingly, deletion of asf1 is lethal in many organisms where it was investigated, and so far, $S$. macrospora and the plant Arabidopsis thaliana are the 
only multicellular organisms where $\Delta$ asf1 mutants are viable [37, 41]. However, the $S$. macrospora mutant is unable to develop mature fruiting bodies (perithecia). It only forms young, immature fruiting bodies (protoperithecia) that do not contain sexual spores [37], similar to the pro44 mutant, which is also blocked a the stage of protoperithecium formation [21]. Several developmental genes are transcriptionally deregulated in the $\Delta$ asf $1 \mathrm{mu}-$ tant strain, but the extent to which ASF1 might regulate gene expression during fungal development and the molecular mechanisms behind this are not yet clear. Therefore, one aim of our analyses was to identify transcriptional changes in the $S$. macrospora $\Delta$ asf1 mutant on a genome-wide basis. Another aim was to address the question if and to what extent regulation by chromatin modifiers and transcription factors is connected to orchestrate multicellular development in ascomycetes. Therefore, in this study we analyzed the functions of the conserved developmental transcription factor PRO44 and the histone chaperone ASF1 during fruiting body development in $S$. macrospora. Both proteins are predicted to act on the regulation of gene expression in the nucleus, and mutants in both genes are blocked at the same stage of development. Thus, we started with the hypothesis that PRO44 and ASF1 might be involved in similar aspects of transcriptional regulation.

\section{Results}

PRO44 localizes to the nucleus and is strongly expressed in the outer layers of protoperithecia

In a previous study, the $S$. macrospora ASF1 was already shown to localize to the nucleus and to interact with histones H3 and H4 [37], whereas the subcellular localization of PRO44 has not yet been determined. To learn more about the localization and molecular function of PRO44, we first generated a pro44 deletion mutant by homologous recombination (Additional file 1: Figure S1), since the previously characterized pro44 mutant carries only a point mutation in the stop codon of pro44 [21]. The $\Delta$ pro44 mutant shows the same phenotype as the original pro44 mutant carrying the point mutation, namely a developmental block at the stage of protoperithecia formation, and the formation of protoperithecia that are submerged in the agar, in contrast to the wild type, which forms protoperithecia at the agar/ air interface. The mutant can be complemented to fertility by transformation with the wild type pro44 gene (Additional file 1: Figure S1).

To analyze the subcellular localization of PRO44, the $\Delta$ pro44 deletion mutant was transformed with a plasmid expressing an egfp-pro44 fusion gene under control of the pro $445^{\prime}$ and $3^{\prime}$ regulatory regions. This resulted in fertile transformants confirming complementation of the sterile phenotype by the egfp-pro44 fusion gene. EGFP fluorescence in hyphae localized in structures stained by DAPI, indicating a nuclear localization of PRO44 as expected for a transcription factor (Fig. 1a).

In a previous analysis, it was found that the pro 44 transcript is strongly expressed in protoperithecia [28]. To check whether a PRO44 accumulation in protoperithecia can also be observed at the protein level, we analyzed the localization of the EGFP-PRO44 fusion protein over a developmental time course (Fig. 1b). As control, a wild type transformant expressing egfp from a constitutive promoter as well as an mKalama-fused histone $\mathrm{H} 2 \mathrm{~B}$ gene was also analyzed. As expected, the wild type control expressing egfp alone showed evenly distributed green fluorescence in all mycelial structures. The mKala$m a$-hh $2 b$-carrying transformant showed blue nuclear fluorescence in all structures, with a stronger fluorescence in the core of developing protoperithecia than in the outer layers. PRO44 was also detected in nuclei of all structures, with strong fluorescence in developing protoperithecia (Fig. 1b). Interestingly, EGFP-PRO44 fluorescence was stronger in the outer layers of developing protoperithecia than in their core. One possibility for such a distribution of fluorescence would be that the core of the spherical protoperithecia was less accessible for fluorescence microscopy, however, the stronger fluorescence of the mKalama-HH2B fusion in the protoperithecial core of the controls indicates that lack of fluorescence from the protoperithecial core in the case of EGFP-PRO44 is not an artefact. Thus, our data indicate that pro44 is strongly expressed in developing protoperithecia not only at the transcript, but also at the protein level, and that PRO44 accumulates most strongly in the outer layers of young fruiting bodies.

\section{PRO44 forms homodimers}

To identify PRO44 interaction partners in S. macrospora, we performed a yeast two-hybrid screen against two $S$. macrospora cDNA libraries that were established previously [42]. Of several putative interaction partners identified in the screen, only PRO44 itself could be confirmed by targeted two-hybrid analyses with full-length cDNAs, suggesting that PRO44 forms homodimers (Fig. 2). Interestingly, during the cloning of cDNA constructs for the two-hybrid analyses based on RNA from mycelia grown for $4 \mathrm{~d}$ in fructification medium, we detected three different splice variants of the second intron of pro44 (Fig. 2a). One splice variant leads to an additional glutamine in the corresponding protein (PRO44-B), whereas the second leads to the addition of the three amino acids asparagine, lysine, and glutamine (PRO44-C). Structure predictions using Phyre2 [43] indicated an alpha-helical structure in this region for all three proteins. All proteins derived from the splice variants interact with each other in all possible combinations (Fig. 2b); therefore, it is not clear if the different proteins have different biological functions. 


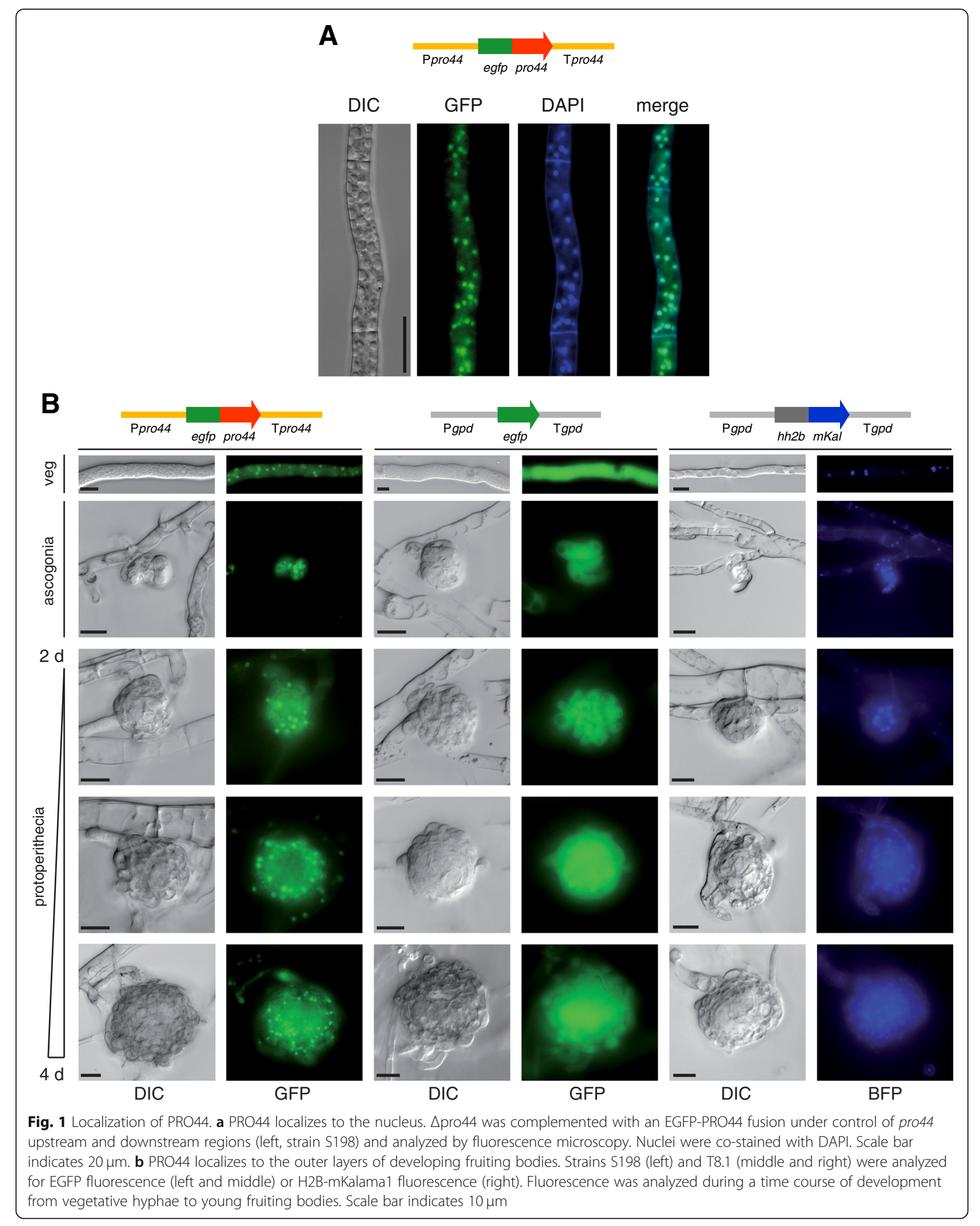




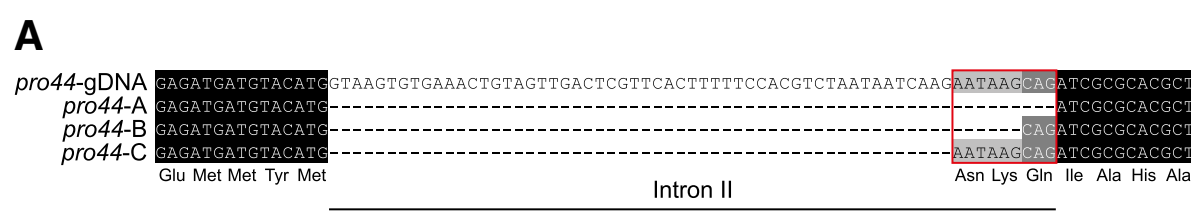

B

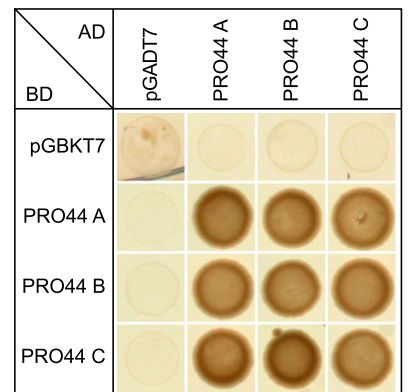

C

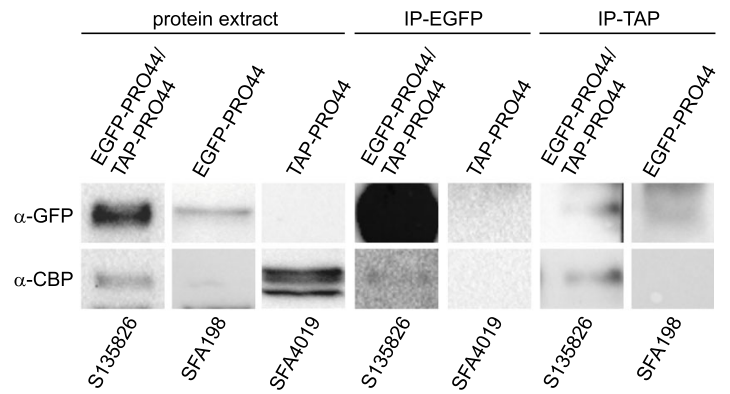

Fig. 2 PRO44 forms homodimers. a Multiple alignment of the genomic region around the second intron in pro44. The three splice variants of pro44 (pro44-A, -B, and -C) are shown. $\mathbf{b}$ Yeast-two-hybrid analysis of interactions of different PRO44 variants resulting from different splice variants. c Co-immunoprecipitation of two differently tagged PRO44 proteins (EGFP- and TAP-tagged proteins in strain S135826, only EGFP-PRO44 in strain SFA198, only TAP-PRO44 in strain SFA4019). The band seen in strain SFA198 (EGFP-PRO44) after TAP-IP and western blot with an antiEGFP antibody is unspecific (for details see Additional file 2: Figure S2)

To confirm the interaction of PRO44 with itself, we performed chromatin immunoprecipitation with two differently tagged PRO44 variants, one with a TAP (tandem affinity purification)-tag, the other with an EGFP tag (Fig. 2c, Additional file 2: Figure S2). Chromatin immunoprecipitation targeting EGFP or the TAP-tag, respectively, was able to pull down both forms of PRO44, confirming the presence of both tagged PRO44 forms in the same protein complex. These data indicate that PRO44 acts (at least) as a homodimer, although larger protein complexes containing PRO44 cannot be excluded.

\section{asf1 plays a role in sexual development, whereas cac2,} rtt106, and crc1 are not essential for this process

The $S$. macrospora ASF1 protein was shown to localize to the nucleus and to interact with histones $\mathrm{H} 3$ and $\mathrm{H} 4$, and the asf1 gene is essential for sexual development [37]. Interestingly, mutants of two other histone chaperone genes for histones $\mathrm{H} 3$ and H4, rtt106 and $c a c 2$, did not display any developmental phenotype. This might suggest that the developmental function of asf1 is specific and not generally an effect of chromatin modifier mutations [37]. Therefore, we wanted to address two questions, namely if other chromatin modifier genes that are transcriptionally upregulated during sexual development are also required for this process, and if the nuclear factors ASF1 and PRO44 are involved in regulating the expression of a similar set of genes.

To address the first question, we generated a $\Delta \mathrm{cac} 2 /$ $\Delta$ rtt106 double mutant (Additional file 3: Figure S3), as well as a novel deletion mutant of the putative chromatin modifier gene SMAC_02795 (crc1, crc domain protein 1, Additional file 4: Figure S4), and double mutants of $c r c 1$ with the three chromatin modifier genes asf1, $c a c 2$, and $r t t 106$ (Additional file 5: Figure S5). The $c r c 1$ gene was chosen because it is upregulated in protoperithecia of the $S$. macrospora wild type, where it is among the 500 most strongly expressed genes [28]. It encodes a CRC (chromatin remodeling complex) subunit domain protein similar to its S. cerevisiae homologs Rsc7 and Swp82. In yeast, Rsc7 and Swp82 are subunits of the chromatin remodeling complexes RSC and SWI/SNF, respectively [44]. These protein complexes are involved in generating nucleosome-free regions upstream of transcribed genes, thereby enabling transcription [45]. In filamentous ascomycetes, two paralogs of Rsc7 and Swp82 can be found; however, at least CRC1 is not clearly orthologous to either of the two proteins (Additional file 6: Figure S6), therefore it was named differently ( $\operatorname{crc} 1$ after its characteristic domain). EGFP fusions of the three proteins CAC2, CRC1, and RTT106 localize to the nucleus, as one would expect for (putative) chromatin modifiers (Additional file 7: Figure S7).

When grown on fructification medium (BMM), $\Delta \mathrm{crc} 1$ is fertile indicating that this gene is not essential for fruiting body formation. To test the degree of redundancy of different chromatin modifier systems with respect to sexual development, we generated double mutants. The double mutants $\Delta \mathrm{crc} 1 / \Delta \mathrm{cac} 2, \Delta \mathrm{crc} 1 / \Delta \mathrm{rtt} 106$, and $\Delta \mathrm{cac} 2 / \Delta \mathrm{rtt} 106$ are fertile (Additional file 8: Figure S8A). However, the 
$\Delta \mathrm{cac} 2 / \Delta \mathrm{rtt} 106$ mutant is sterile when grown on minimal medium, whereas the single mutants $\Delta \mathrm{cac} 2$ and $\Delta \mathrm{rtt} 106$ are fertile under these conditions (Additional file 8: Figure S8B). This result suggests that $c a c 2$ and $r t t 106$ might have partially redundant functions, and that these functions might be more important under stress conditions like nutrient deprivation. However, loss of both genes does not generally lead to a block in fruiting body formation as the double mutant is fertile on the more nutrient-rich BMM medium.

With respect to double mutants with $\Delta$ asfl, we were able to generate a $\Delta \mathrm{crc} 1 / \Delta$ asf1 double mutant, which is sterile, similar to the $\Delta$ asf1 single mutant (Additional file 8: Figure S8). We were not able to generate double mutants of asf 1 and cac 2 or rtt106 by genetic crossing, suggesting that a combination of these deletions might be lethal. This might suggest that cac 2 and rtt106 can perform some functions of asf1, but not those related to fruiting body formation.

So far, the analysis of chromatin modifier genes asf1, $c a c 2$, crc1, and $r t t 106$ revealed that only asf 1 is essential for fruiting body formation, whereas cac2 and rtt106 might have redundant functions in this process under nutrient-limiting conditions.

\section{RNA-seq analysis reveals distinct roles for asf1 and pro44 in sexual development}

As ASF1 and PRO44 both are required at the transition from protoperithecia to peritheica, and predicted to influence gene expression, we hypothesized that both genes might be involved in regulating similar subsets of genes. Therefore, we performed RNA-seq to study the functions of both genes with respect to transcription. RNA-seq analyses were carried out with the wild type and the $\Delta$ asf1 and $\Delta$ pro44 mutants grown as surface cultures, which leads to sexual development in S. macrospora. Furthermore, we analyzed the transcriptome of protoperithecia that were isolated by laser microdissection from the $\Delta$ pro 44 mutant, because pro 44 is preferentially expressed in young fruiting bodies as described above. The $\Delta$ asf1 mutant did not produce protoperithecia when grown on the slides required for microdissection, therefore no protoperithecial RNA could be isolated from this mutant. The RNA-seq data were analyzed in combination with transcriptome data from protoperithecia of the wild type and developmental mutants pro1 and $\Delta$ nox 1 that were generated previously $[28,46]$ (Additional file 9: Table S1). The pro1 and $\Delta$ nox $1 \mathrm{mu}-$ tants are similar to $\Delta$ pro 44 and $\Delta$ asf1 in that they are only able to form protoperithecia, but no mature perithecia.

When comparing gene expression of all analyzed conditions versus wild type sexual mycelium, it became apparent that the number of differentially regulated genes is much larger when comparing protoperithecia versus sexual mycelium (Fig. 3, middle and bottom row) than in comparisons of sexual mycelium of the mutants $\Delta$ asf1 or $\Delta$ pro44 against wild type (Fig. 3 , top row). This is consistent with previous findings [28] and confirms that gene expression in young fruiting bodies is vastly different from expression in total sexual mycelium, which in S. macrospora consists mostly of vegetative hyphae with the fruiting bodies comprising only a small part of the total bulk of the sexual mycelium. The finding that expression patterns are very different in protoperithecia compared to total sexual mycelium is also supported by an analysis of RPKM (read per kilobase per million counted reads) values, which reflect the overall expression of a gene under the given conditions. Clustering of correlation coefficients based on RPKM values for each sequenced sample clearly shows grouping of the protoperithecia samples apart from the sexual mycelia samples (Additional file 10: Figure S9). Within the protoperithecia samples, the wild type protoperithecia cluster separately from the samples of the three sterile mutants, indicating that there are common expression patterns characteristic of mutants with a block at this developmental stage.

Within the sexual mycelia samples, the wild type and $\Delta$ pro44 cluster together, while the $\Delta$ asf1 samples cluster separately (Additional file 10: Figure S9). This was somewhat surprising given that the mutants are both sterile with a block at the same developmental stage; however, it might be explained by a distinct tendency of genes with overall low expression to be upregulated specifically in the $\Delta$ asf1, but not in the $\Delta$ pro44 mutant (Fig. 3 , top row). In all conditions except $\Delta$ asf1 vs. wild type, the significantly differentially expressed genes are evenly distributed above and below the expression level of the wild type ( $y=0$ in Fig. 3), and most differentially expressed genes have a medium to high overall expression level (on the x-axis). In $\Delta$ asf1, however, there is a shift towards the more weakly expressed genes to be upregulated. We confirmed this tendency by analyzing genes that have overall low or high expression in the wild type (RPKM in wild type $<1$ or $>5$, respectively) for their expression ratios in the two mutants versus the wild type (Fig. 4). The distribution of expression ratios is shifted towards upregulation only in the comparison of $\Delta$ asf1 versus wild type for genes with overall low expression. Thus, asf 1 appears to be acting as a suppressor of weakly or not expressed genes during sexual development. Overall, the transcriptome analyses show that both asf1 and pro 44 are required for correct gene expression during sexual development, but that they have different effects on genome-wide patterns of gene expression.

Among the genes that are upregulated in the $\Delta$ asf1 mutant is $p k s 4$, a polyketide synthase gene that was previously shown to be essential for fruiting body development [47] (Additional file 11: Figure S10). Expression of pks4 

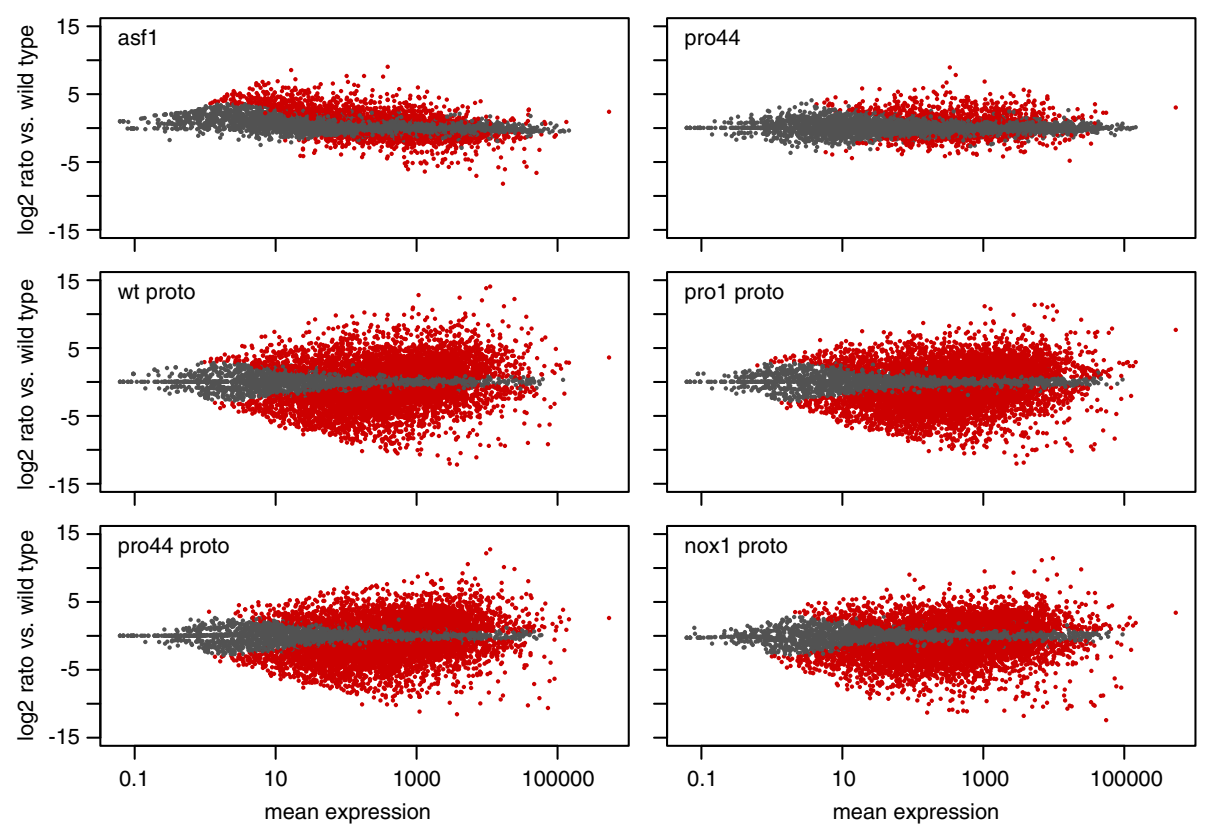

Fig. 3 MA plots of expression ratios for six conditions compared to wild type (y-axis) vs. mean expression (x-axis). Ratios and mean expression were calculated with DESeq2. Significantly differentially expressed genes (at padj $<0.1$ ) are shown in red. The following six conditions were compared to wild type sexual mycelium: asf1, sexual mycelium from $\Delta$ asf1; pro44, sexual mycelium from $\Delta$ pro 44 ; wt proto, wild type protoperithecia; pro1 proto, protoperithecia from mutant pro1; pro44 proto, protoperithecia from $\Delta$ pro 44 ; nox 1 proto, protoperithecia from $\Delta$ nox 1

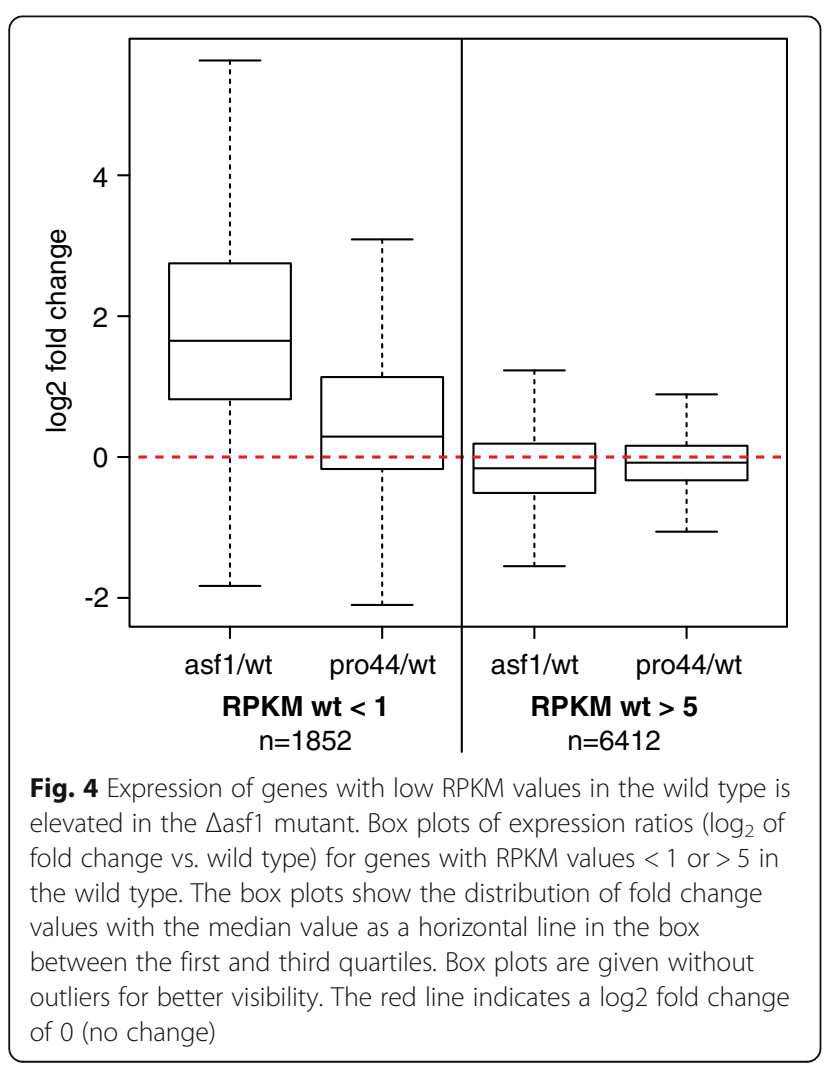

was verified by RT-qPCR and found to be specifically upregulated in $\Delta \mathrm{asf} 1$ and the $\Delta \mathrm{asf} 1 / \Delta \mathrm{crc} 1$ double mutant, but not in mutants of cac2, rtt106, pro1 or pro44 (Additional file 11: Figure S10B). However, the majority of the pks and nrps genes present in the S. macrospora genome is differentially regulated in at least one of the analyzed mutants or conditions (Additional file 11: Figure S10A). A role in fruiting body development has so far been found for $p k s 4$ and $p k s 7$, the latter being required for melanin biosynthesis in S. macrospora [48], but it is tempting to speculate that other secondary metabolism genes that are differentially expressed during development might play a role in this process.

\section{Nucleosome spacing and positioning around transcriptional start sites are wild type-like in the asf 1 mutant, but cytosine methylation is reduced}

The RNA-seq data showed that asf1 has a very distinct influence on gene expression, which is unique among the $S$. macrospora mutants tested so far. As a histone chaperone, ASF1 is predicted to directly or indirectly influence chromatin structure, and one way for ASF1 to regulate gene expression might be an influence on genome-wide changes of nucleosome positioning, thereby changing the accessibility of promoter regions or gene bodies for transcription. To test this possibility, we performed micrococcal nuclease (MNase)-sequencing with sexual mycelia of the wild type and the $\Delta$ asf1 mutant. MNase preferentially 
digests linker DNA between nucleosomes. The remaining nucleosome-bound DNA can be isolated and sequenced [49]. The analysis of MNase-seq data from two independent biological replicates for each strain revealed that the distribution of distances between adjacent nucleosome pairs in the asf1 mutant does not differ from the wild type (Additional file 12: Figure S11). In both strains, the distribution peaks at a nucleosome distance around $180 \mathrm{bp}$. This is consistent with each nucleosome consisting of $147 \mathrm{bp}$ of DNA wrapped around a histone octamer, and nucleosomes separated by linkers of varying length, usually from 10 to $80 \mathrm{bp}$ [49-51].

It was shown in yeast and metazoa that nucleosomes are unevenly distributed around transcriptional start sites (TSSs), with a nucleosome-depleted region (NDR) directly upstream of the TSS, and regularly spaced nucleosomes downstream of the TSS $[49,50,52-55]$. In human cell lines, this pattern of nucleosome distribution is more pronounced in actively transcribed genes [54]. To determine whether similar patterns can be observed in S. macrospora, and whether lack of asf 1 leads to different nucleosome patterns, we analyzed nucleosome positioning around TSS in genes (Fig. 5). For this analysis, we differentiated between genes with overall weak or strong expression (RPKM in wild type $<1$ or $>5$, respectively), as these are genes that show different degrees of differential gene expression in the $\Delta$ asf1 strain as described above. NDRs upstream of TSSs were observed in both the wild type and the $\Delta$ asf1 strain, and in both strains, the NDRs were larger in the more strongly expressed genes (Fig. 5). Thus, the nucleosome distribution around the TSSs is correlated with gene expression levels in S. macrospora, similar to findings in other eukaryotes. There was no overall difference in the nucleosome distribution around the TSSs between the wild type and $\Delta$ asf1. Together with the analysis of nucleosome distances (Additional file 12: Figure S11), this indicates that there are no significant differences in nucleosome number, spacing, and general distribution around TSSs in the asf1 mutant strain. This indicates that overall nucleosome positioning is not affected by the lack of asf1. However, this still leaves other aspects of nucleosome metabolism that might be different in the $\Delta$ asf1 strain and were not measured in the MNase-seq experiments, e.g. short-term nucleosome positioning at individual genes, nucleosome turnover, or histone modifications.

In the yeast $S$. cerevisiae, Asf1 was shown to be involved in regulation of gene expression by histone modifications through recruiting the histone acetyltransferase Rtt109 [38, 56, 57]. The molecular mechanisms of ASF1 action in filamentous fungi have not been analyzed yet. However, histone modifications were analyzed in $N$. crassa, where methylation of lysine 9 of histone $\mathrm{H} 3$ was shown to be essential for DNA methylation and
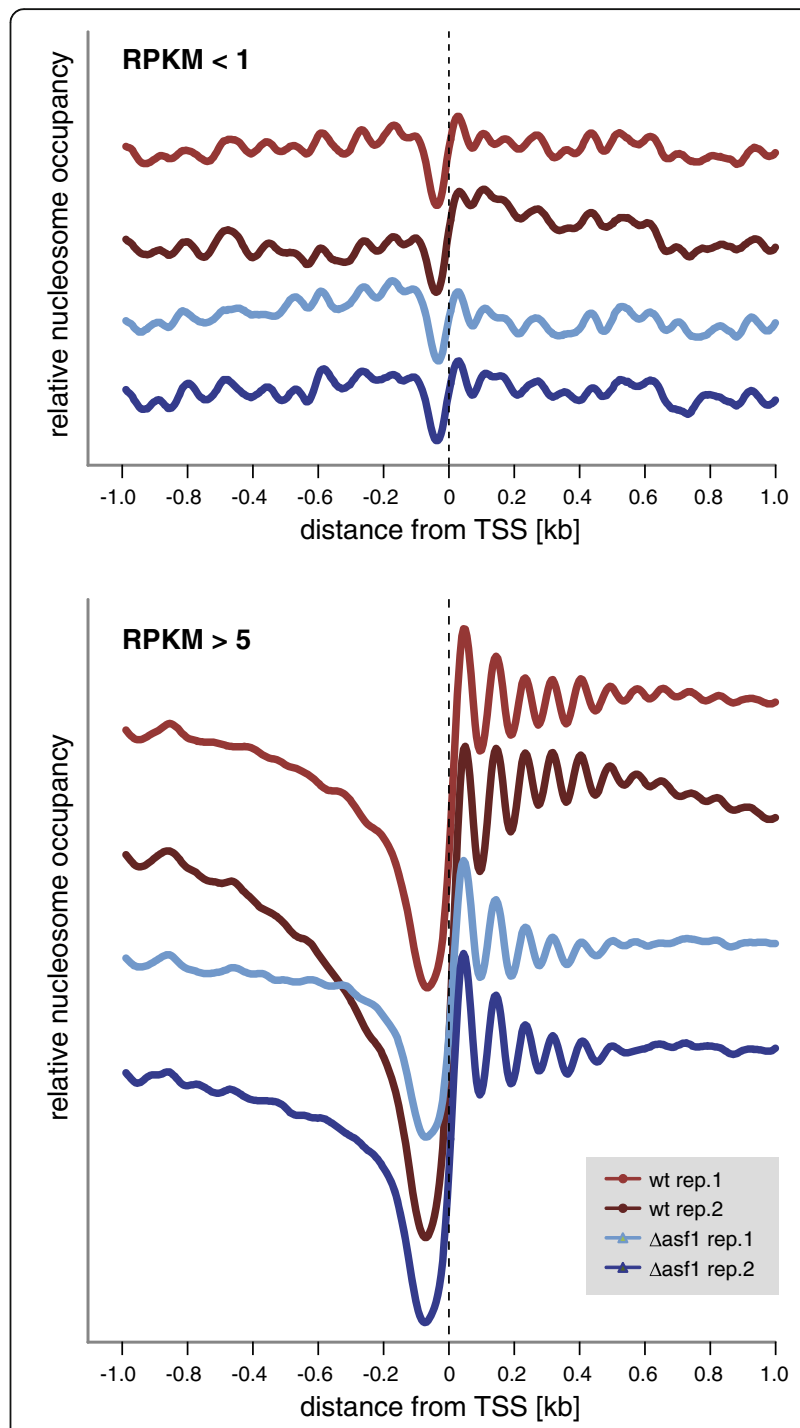

Fig. 5 Nucleosome profiles around transcriptional start sites in the wild type and $\triangle \mathrm{asf1}$. Results are shown for two independent biological replicates for each strain. To account for differences in read coverage, nucleosome occupancy was normalized by setting the highest occupancy for each gene to 1 before calculating averages. Averages at each position were calculated for genes with RPKM values in the wild type of $<1$ or $>5$, respectively. The $y$-axis gives the relative nucleosome occupancy within each sample (the scale of the $y$-axis is the same within each sample, graphs were stacked along the $y$-axis for better visibility)

heterochromatin formation. In this fungus, H3K9 methylated histone $\mathrm{H} 3$ is recognized by heterochromatin protein 1 (HP1), which recruits DNA methyltransferase DIM-2, which is responsible for all cytosine methylation in $N$. crassa [32, 58, 59]. In filamentous fungi, possible connections between histone chaperone functions, histone modifications, and DNA methylation have not yet been studied. To test if asf1 plays a role in DNA methylation in $S$. macrospora, we performed bisulfite 
sequencing (BS-seq) for the wild type and the $\Delta$ asf1 mutant in two independent biological replicates. BS-seq uses sodium bisulfite treatment prior to sequencing to convert cytosines to uracils, whereas methylcytosines remain unmodified. Uracils are read as thymines during sequencing, and by comparing the modified DNA with the reference sequence, the methylation state of the analyzed DNA can be inferred [60, 61]. To address the question whether methylation rates in $\Delta$ asf1 differ depending on genomic features encoded by the corresponding DNA sequences, we analyzed methylation rates separately in gene bodies (annotated genes including UTRs and introns), upstream regions (500 bp upstream of annotated gene start), and repeat regions (Fig. 6a, Additional file 13: Table S2). Overall methylation rates were higher in repeat regions than in gene bodies and upstream regions, suggesting that DNA methylation might be a mechanism of transposon silencing, similar to what was observed in other ascomycetes [62-64]. Methylation was lower in $\Delta$ asf1 compared to the wild type in all analyzed types of DNA features (Fig. 6a). This was also the case when looking at those groups of genes that show different expression patterns in the asf1 mutant, namely genes with overall low or high expression (see above). Both groups of genes showed overall lower methylation rates in $\Delta$ asf1, both within gene bodies as well as in upstream regions (Fig. 6). Thus, reduced DNA methylation might be involved in the observed changes in gene expression in $\Delta$ asfl, but additional mechanisms have to be proposed for the effects found specifically for genes with overall low expression.

\section{pro44 is required for correct expression of genes in protoperithecia and mycelia}

The RNA-seq data for sexual mycelia from asf 1 and pro44 mutants indicated that both genes are regulating distinct aspects of sexual development as described above. For the $\Delta$ pro44 mutant, we also generated RNA-seq data for protoperithecia of $\Delta$ pro44, the last developmental stage that the mutant is able to reach, because the pro44 gene was previously found to be transcriptionally upregulated in protoperithecia [28], and fluorescence microscopy showed the PRO44 protein to be localized in the outer layers of these structures (Fig. 1). To analyze which groups of genes might be directly or indirectly regulated by pro44 in protoperithecia, a FungiFun2 analysis based on the FunCat classification was performed for the RNA-seq results $[65,66]$. Among the upregulated genes in protoperithecia of any of the three mutants (pro1, $\Delta$ pro44, or $\Delta$ nox1), there were no significantly overrepresented FunCat categories; however among the downregulated genes, a number of FunCat categories were significantly overrepresented in at least one of the mutant strains (Fig. 7). Interestingly, in $\Delta$ pro44 protoperithecia, the categories extracellular metabolism, secretion, and cell rescue were overrepresented among the downregulated genes, indicating that pro 44 is involved in organizing these processes in the developing fruiting body. This fits well with the presence of the protein in the outer layers of the protoperithecium, where cells differentiate to form the perithecium wall, which requires major modifications of the cell wall compared to vegetative cells, and which is the location of first
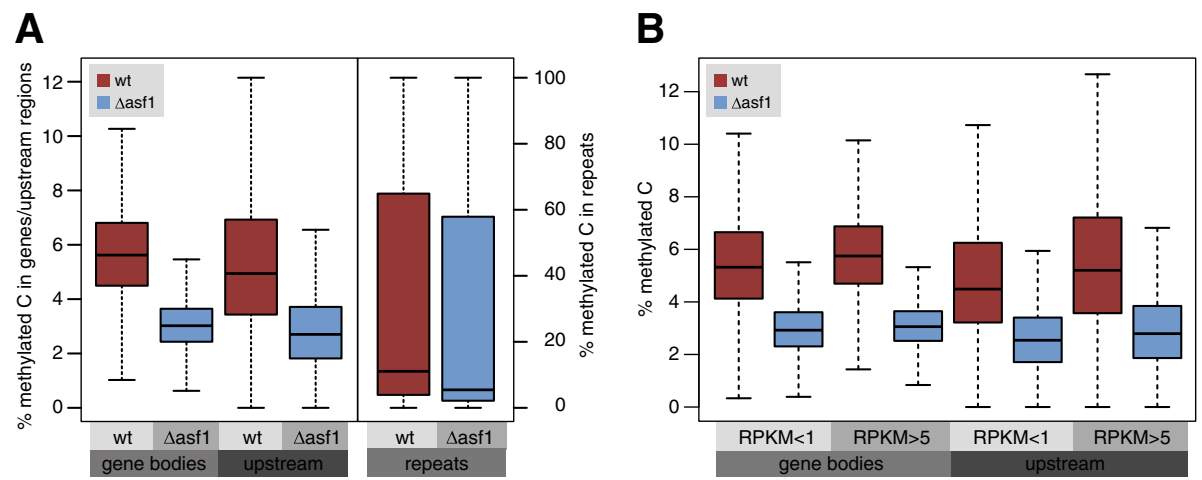

Fig. 6 Analysis of cytosine methylation by bisulfite sequencing (BS-seq) in the wild type and $\triangle$ asf1. a Methylated cytosines (at least 5\% methylation for a cytosine to be counted as methylated) were counted within gene bodies (exons and introns of gene, i.e. the regions contained in the primary transcript), upstream regions (500 bp upstream of the annotated gene body), and annotated repeat regions. The boxplots show the distribution of the percentages of methylated cytosines, with median value as a horizontal line in the box between the first and third quartiles. Outliers were left out for better visibility. Student's t-test showed that mean values of wild type and $\triangle$ asf1 are significantly different from each other for each group of features (gene bodies, upstream regions, repeats). $\mathbf{b}$ Boxplot of percentages of methylated cytosines in different subsets of genes. On the left, methylation within gene bodies was analyzed, on the right, methylation in upstream regions, in both cases for genes with RPKM values in the wild type of $<1$ or $>5$, respectively. Outliers were left out for better visibility. The median value is shown as a horizontal line in the box between the first and third quartiles. Student's t-test showed that for each RPKM group $(<1$ or $>5)$, the wild type and $\Delta$ asf1 mean values are significantly different from each other $(p<0.05)$ 


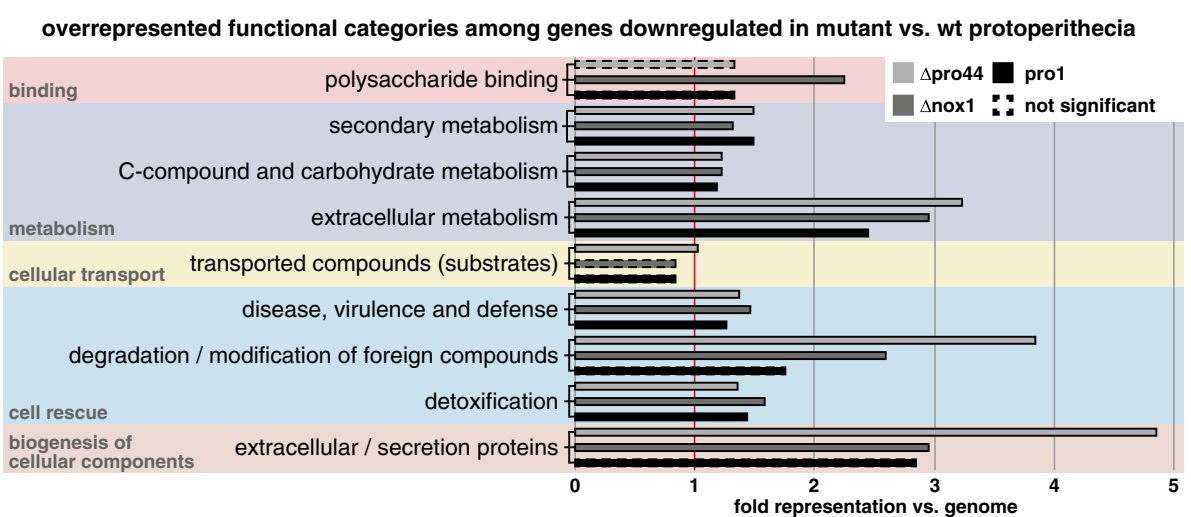

Fig. 7 Fungifun2 analysis of genes that are downregulated in mutant protoperithecia compared to wild type protoperithecia. The selected classification ontology was FunCat. Fold representation vs. genome of the first subcategory is indicated in the bar graphs. Main categories to which the subcategories belong are indicated in gray on the left. Only categories are shown that are significantly enriched $(p<=0.05)$ in at least one of the mutants

contact for potential predators that feed on fungal fruiting bodies.

Compared to the number of differentially expressed genes in protoperithecia, fewer genes are differentially regulated in sexual mycelia of the $\Delta$ pro44 mutant. However, among the differentially regulated genes is cas4, which is upregulated in $\Delta$ pro44 even more strongly than in the $\Delta$ asf1 mutant (Additional file 14: Figure S12). cas4 is one of four genes encoding carbonic anhydrases in $S$. macrospora [67, 68]. Carbonic anhydrases catalyze the conversion of $\mathrm{CO}_{2}$ to bicarbonate $\left(\mathrm{HCO}_{3}{ }^{-}\right)$, which is an important metabolite in many physiological reactions. Furthermore, $\mathrm{CO}_{2}$ can serve as signaling molecule, e.g. for pathogenic adaptations in Cryptococcus neoformans and Candida albicans [69]. In S. macrospora, three genes (cas1, cas 2 , and cas 3 ) encode carbonic anhydrases of the $\beta$-class that are involved in fruiting body formation and show functional redundancy [70]. The cas4 gene encodes the only $\alpha$-class carbonic anhydrase of $S$. macrospora, and deletion of the gene leads to reduced ascospore germination [71]. Interestingly, a quadruple mutant of all four carbonic anhydrase genes forms fruiting bodies within the agar instead of at the agar/air interface [71], and a possible mechanism for involvement of pro44 and cas 4 in regulating the correct spatial localization of fruiting bodies is discussed below.

\section{The putative transcription factor gene asm2}

(SMAC_09436) is dependent on pro44 for upregulation in protoperithecia, and is involved in ascospore maturation and discharge

Among the genes that are transcriptionally downregulated in protoperithecia of the pro44 mutant compared to wild type protoperithecia was SMAC_09436 (Additional file 9: Table S1). The gene encodes a protein with a GAL4-like zinc cluster domain and a fungal transcription factor domain, and therefore might function as a transcription factor. It has orthologs in other Sordariomycetes, but not outside of this group of fungi (Additional file 15: Figure S13). To determine if SMAC_09436 is not only regulated by pro44, but also involved in fruiting body formation itself, we generated a deletion mutant (Additional file 16: Figure S14). Vegetative growth of the $\triangle$ SMAC_09436 mutant was normal, and fruiting bodies were formed after $7 \mathrm{~d}$ similar to the wild type. The only difference to the wild type was in the orientation of the fruiting bodies, which in $\triangle$ SMAC_09436 was not in all cases perpendicular to the growth medium (Additional file 17: Figure S15). However, the most significant difference to the wild type is a spore maturation defect in the mutant (Fig. 8). In the wild type, the eight spores of an ascus mature at an even rate, i.e. the eight spores within an ascus have the same maturation stage, with the first asci with eight black ascospores visible after $7 \mathrm{~d}$ (Fig. 8). In the mutant, the eight ascospores of an ascus showed uneven maturation rates, resulting in asci with mature and immature spores within one ascus, even after prolonged incubation of $14 \mathrm{~d}$ (Fig. 8). Further, in contrast to the wild type, where only mature ascospores are discharged, the mutant discharges a mixture of mature and immature ascospores (Fig. 8). Both phenotypes (uneven ascospore maturation and discharge of immature spores) could be complemented by transformation with the wild type SMAC_09436 gene (Fig. 8). Based on the defect in ascospore maturation, we named the corresponding SMAC_09436 gene asm2 (ascospore maturation 2) (we did not name it asm1 to avoid confusion with the $N$. crassa asm-1 gene, which is also involved in fruiting body development, but is not a homolog of SMAC_09436).

Correct expression of asm 2 in protoperithecia is dependent on pro44, and if the pro44-dependent transcriptional activation of asm 2 were required for fruiting 


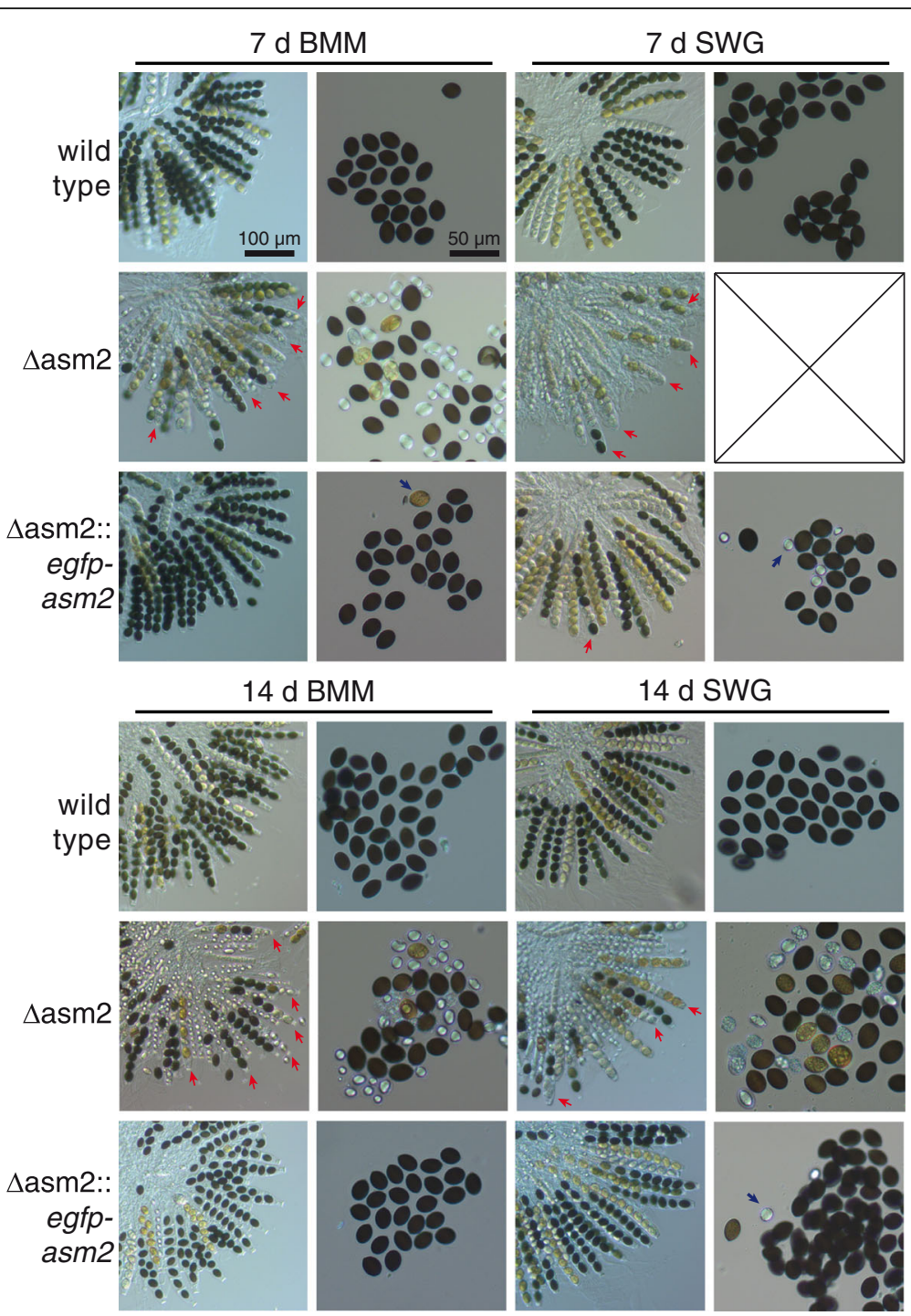

Fig. 8 Deletion of the asm2 (SMAC_09436) gene leads to defects in ascospore maturation. $\triangle$ asm2 (DSMAC_09436, spore isolate S148783) and a complemented transformant (spore isolate RL726) were grown on full medium (BMM) or defined medium (SWG) at $25^{\circ} \mathrm{C}$ for the indicated times. Scale bars are the same for all ascus rosette pictures (left column for each time point) and pictures of spores discharged on the lid of the petri dish (right column for each time point), respectively. In the asm2 deletion strain, many ascospores remain less pigmented even after $14 \mathrm{~d}$, and many asci contain mature and immature spores (red arrows), which does not occur in the wild type where spores within an ascus have the same maturation stage. In contrast to the wild type, which only discharges mature (black) ascospores, the deletion mutant discharges immature ascospores. The complemented transformant shows wild type-like ascus and ascospore maturation, and except for few less pigmented spores (blue arrows), only mature spores are discharged

body formation, any phenotypic defects of $\Delta$ asm 2 should occur in developing fruiting bodies, and at a later stage than the defect in $\Delta$ pro44. This is consistent with the phenotype of the $\Delta$ asm 2 mutant, which is restricted to ascospore maturation, i.e. in later stages of fruiting body formation than protoperithecial development.

\section{Discussion}

Fruiting body formation in ascomycetes is a complex process involving the concerted actions of many genes.
There are a number of transcription factor genes known to be essential for fruiting body development; in addition, several studies in recent years have identified genes that are required for development and encode proteins involved in chromatin modification, pointing to a role for chromatin organization in the spatio-temporal regulation of gene expression during fruiting body morphogenesis [7]. In the basidiomycete Coprinopsis cinerea, two recent studies identified the genes Cc.snf5 and Cc.apr9 that are required for fruiting body formation 
$[72,73]$. Cc.snf5 encodes a putative subunit of the SWI/ SNF chromatin remodeling complex, while Cc.arp9 encodes an actin-related protein that is predicted to be a subunit of the SWI/SNF and RSC chromatin remodeling complexes. These data imply a role for chromatin remodeling in fruiting body development of mushrooms. In ascomycetes, two Fusarium graminearum homologs of members of the $S$. cerevisiae Set3 complex, HDF1 and FGL1, are required for fruiting body formation. The yeast Set3 complex contains several histone deacetylases (HDAC) and regulates HDAC activity [33, 34]. In Aspergillus nidulans, analyses of interaction partners of the velvet protein VeA identified two methyltransferases, VipC and VapB, that can interact with VeA depending on external signals, and inhibit sexual development. Analysis of histone modifications in $v a p B$ overexpression strains indicated that $\mathrm{VapB}$ might be involved in histone H3 lysine 9 trimethylation (H3K9me3) [36]. The VeA protein contains a velvet domain, and velvet domain proteins were only recently shown to be DNA-binding transcription factors [74-76]. Another developmental gene of $A$. nidulans, $r t f A$, was identified as a suppressor of $\Delta$ veA secondary metabolism phenotypes, and encodes a putative Paf complex protein [35]. In S. cerevisiae, the Paf complex is required for transcription-associated histone modifications [77]. Thus, the physical and genetic interactions of the velvet protein VeA suggest a tightly controlled regulation of specific transcription factors and the chromatin landscape [78].

In this study, we analyzed the role of the chromatin modifier genes asf1, cac2, crc1, and rtt106 in fruiting body formation in S. macrospora. Among these four genes, only asf1 is essential for this process, while cac2 and $r t 106$ appear to have redundant functions during development under nutrient-limiting conditions. In contrast to several other ascomycetes, which form fruiting bodies only under conditions of nutrient-limination, $S$. macrospora develops fruiting bodies on complete medium [79, 80]. It might be possible that cac2 and rtt106 are involved in processes that sense or regulate nutrient availability for the energy-consuming task of perithecium development.

Our analysis of several chromatin modifier genes points to a specific role for asf1 in fruiting body morphogenesis, and this was confirmed by transcriptome analysis, which revealed an unusually high number of genes with overall low expression being upregulated in the $\Delta$ asf1 mutant. Thus, asf1 appears to act as a repressor of genes with low or no expression during fruiting body formation. A repressive role for Asf1 was also recently shown in $S$. pombe, where Asf1 is required for repression of the $f b p 1$ gene during glucose growth on glucose [81]. The transcriptome pattern observed in the $S$. macrospora $\Delta$ asf1 mutant is distinct from the pattern observed in the transcription factor mutant $\Delta$ pro44, which shows an equal number of up- and downregulated genes without a preference for deregulation of genes with low overall expression. Thus, the starting hypothesis that PRO44 and ASF1 might be involved in similar aspects of transcriptional regulation could not be confirmed. While both PRO44 and ASF1 are essential for sexual development and lead to a block of morphogenesis at the stage of protoperithecia, the currently available data indicate that they are involved in distinct aspects of fruiting body formation.

One way for ASF1 to influence transcription would be an effect on nucleosome positioning, especially at TSSs. However, our MNase-seq analyses showed that the distribution of nucleosome pair distances as well as the positioning of nucleosomes around TSSs is not changed in the asf1 mutant compared to the wild type. By these analyses, we cannot exclude effects of asf1 on nucleosome turnover as was observed in at the PHO5 gene promoter in yeast [82-85], or short-lived nucleosome positioning effects, but it is also possible that the effect of asf1 on transcript levels depends on other chromatin modifications. In yeast, it was shown that Asf1 promotes histone $\mathrm{H} 3$ acetylation at lysine 56 by the histone acetyltransferase Rtt109 [57, 86, 87]. However, while a number of proteins involved in histone modifications have been studied in filamentous fungi $[29,88]$, it is not yet known if ASF1 is required for their function.

In $N$. crassa, histone modification in the form of $\mathrm{H} 3$ lysine 9 trimethylation is required for DNA methylation that leads to heterochromatin formation [32]. Thus, a possible linkage between histone chaperone function and changes in gene expression might be in the (indirect) regulation of DNA methylation leading to gene silencing. To test this, we performed BS-seq of the wild type and $\Delta$ asf1. In the asf 1 mutant, we found a reduction of methylation that was present in all analyzed features (gene bodies, upstream regions and repeat regions). It is possible that the overall lower methylcytosine content in the mutant alters chromatin structure in a way that disturbs normal regulatory events leading to transcriptional expression or silencing of genes. However, another hypothesis would be that ASF1-dependent histone modifications lead to changes in gene expression, and that methylation differences are a consequence rather than a cause of these expression changes. Future studies of histone modifications will be needed to distinguish between these hypotheses.

With respect to the function of chromatin modifiers in cellular differentiation, it was recently shown in mammals that repression of the histone chaperone CAF-1 leads to faster dedifferentiation of somatic cells to stem cells. This is mediated by improved accessibility of chromatin structures at enhancers important for cell fate reprogramming 
as well as localized changes in methylation of lysine 9 at histone H3, a heterochromatin mark $[89,90]$. Therefore, chromatin modifiers might promote developmental transitions by enabling genome-wide changes in chromatin structure that lead to transcriptional reprogramming. Our RNA-seq analysis shows that deletion of asf1 leads to massive, distinct transcriptome changes, suggesting similar functions for asf1 in fungi. One possible hypothesis would be that there are several genes essential for downstream developmental processes among the genes activated or repressed by ASF1-mediated chromatin changes. Another hypothesis might be that genome-wide chromatin changes in the absence of asf1 lead to an overall chromatin state that is sensed by the cells and non-permissive for further development. The nature and function of chromatin changes mediated by ASF1 will be the topic of future studies.

PRO44 belongs to the GATA transcription factors, which constitute a small protein family in filamentous ascomycetes, with only six genes in $N$. crassa [91], all of which have orthologs in S. macrospora. In this study, we showed that PRO44 forms homodimers. In filamentous ascomycetes, dimerization between GATA factors was previously shown in several cases, but not for PRO44 orthologs. Known cases include homo- and heterodimerization of the white collar proteins WC-1 and WC-2, which form the white collar complex (WCC) involved in regulating light responses and circadian rhythmicity in $N$. crassa [92, 93]. Another example is the interaction between the GATA factors AreA and AreB in Fusarium fujikuroi [94]. Both factors play a role in nitrogen regulation in several ascomycetes [95], although the $N$. crassa are $B$ ortholog asd 4 is involved in sexual development rather than nitrogen regulation, and forms homotetramers [96]. For PRO44, the homodimerization shown in this study is the second type of interaction shown for this protein, the first being an interaction of the PRO44 ortholog SUB-1 with the $\mathrm{Zn}(\mathrm{II})_{2} \mathrm{Cys}_{6}$ transcription factor FF-7 in $N$. crassa [26]. Interestingly, the GATA factor genes $s u b-1$ and $w c-2$ are required for light-dependent eviction of nucleosomes at their DNA binding sites, whereas $f f-7$ is not [26]. In A. nidulans, the GATA factor AreA is required for chromatin remodeling at the bidirectional promoter of the nitrogen metabolism genes niiA and niaD, and similar findings were made for a mammalian GATA factor [97-99]. In N. crassa, it was shown that histone $\mathrm{H} 3$ lysine 14 acetylation at the promoter of the light-inducible al-3 gene depends on WC-1, which binds to the histone acetyltransferase NGF-1 [100, 101]. The WC-1 homolog LreA of A. nidulans interacts with the histone acetyltransferase GcnE and the histone deacetylase HdaA [102]. Thus, GATA factors in fungi may serve as pioneer factors that access nucleosomal DNA and initiate regulatory events including opening of chromatin for other transcription factors, similar to findings in mammals [103]. However, whether PRO44 orthologs have a function in reprogramming chromatin during fruiting body development remains to be elucidated.

In addition to a block at the stage of protoperithecium formation, the $\Delta$ pro44 mutant is characterized by the formation of protoperithecia that are submerged in the agar instead of differentiating only at the agar/air interface. Thus, pro44 is required for the correct localization of sexual structures within the mycelium. One possible regulatory pathway that might enable the fungus to sense the agar/air interface might involve the cas4 gene, which is upregulated in $\Delta$ pro44 mycelium compared to the wild type. A quadruple mutant of cas 4 and the other three carbonic anhydrase genes in S. macrospora was previously shown to have a similar phenotype with submerged perithecia [71]. One might speculate that different $\mathrm{CO}_{2}$ concentrations in the agar versus the air act as primary signals for vegetative growth versus sexual development, and that conversion of $\mathrm{CO}_{2}$ to bicarbonate by carbonic anhydrases is part of the signaling pathway. If pro44 acted downstream of this conversion, lack of pro44 might lead to increased cas 4 expression through a feedback mechanism activated when the signal for elevated $\mathrm{CO}_{2}$ concentrations is not received. In addition, lack of signal might lead to mislocalized protoperithecia that are formed in the agar if the signal generated by high $\mathrm{CO}_{2}$ concentrations is blocked. Another mutant with a phenotype of submerged perithecia is the adenylyl cyclase mutant $\Delta$ sac1 [104], therefore it might be hypothesized that a $\mathrm{CO}_{2}$-dependent spatial sensing mechanism might involve pro44, sac1, and carbonic anhydrases. In the pathogenic ascomycete Candida albicans, it was shown that $\mathrm{CO}_{2}$ acts as a signaling molecule for pathogenic development, and that a carbonic anhydrase and adenylyl cyclase are involved in this process $[105,106]$. In the pathogenic basidiomycete Cryptococcus neoformans, a carbonic anhydrase was found to mediate the $\mathrm{CO}_{2}$-dependent inhibition of cell-cell fusion during sexual development [107]. Thus, it is possible that $\mathrm{CO}_{2}$-sensing mechanisms involving carbonic anhydrases and adenylyl cyclases are evolutionary old signaling pathways in fungi that adapted during evolution to mediate different morphogenetic transitions.

Among the genes that are downregulated in $\Delta$ pro44 protoperithecia compared to wild type protoperithecia are many that are predicted to be involved in secretion, extracellular metabolism, and cell rescue. Combined with the finding that PRO44 is most prominently found in nuclei of cells in the outer layer of the protoperithecium wall, this might indicate that PRO44 is involved in morphogenesis of the rigid perithecium shell. This process requires many tissue differentiations as well as 
the deposition of extracellular material on the surface of the fruiting body at the protoperithecial-perithecial transition [10]. In a recent study of another sterile mutant, we identified the $s p d 4$ gene, which is also essential for perithecial development. Interestingly, the SPD4 protein localizes to the ascogonial coils within the developing protoperithecium, but not to the outer layers [108]. The molecular function of SPD4 is unknown, as the protein does not have any known functional domains, but future analyses will focus on the roles of differentially expressed genes like pro44 and spd4 within the tissues where the corresponding proteins are localized.

Among the genes that are upregulated in wild type protoperithecia compared to mycelium, but downregulated in protoperithecia of the pro 44 mutant compared to wild type protoperithecia is asm2 (SMAC_09436). Generation of a deletion strain and complemented transformants for asm 2 showed that the gene is required for correct ascospore maturation. This phenotype is what one would expect for a gene involved in fruiting body development that is activated by pro44, namely being needed later than pro44 itself, and with a phenotype apparent in the developing fruiting body, where asm2 is preferentially expressed. Based on the domain architecture of ASM2, the protein is predicted to function as a transcription factor. Thus, the results support the hypothesis that the putative transcription factor ASM2 is acting downstream of PRO44, which itself is dependent on the transcription factor PRO1 for correct expression in protoperithecia [28]. However, based on the available data it is not yet possible to distinguish between a direct and an indirect regulation of asm2 by PRO44.

\section{Conclusions}

In summary, previous results [28] and the current study indicate that the transcription factors PRO1, PRO44, and ASM2 might act sequentially in a genetic network of transcription factors required for the correct spatio-temporal development of mature fruiting bodies. Based on transcriptome analyses, PRO44 and ASF1 have distinct roles in sexual development, and future analyses will focus on elucidating where chromatin modification and transcriptional regulation meet to orchestrate multicellular development in ascomycetes.

\section{Methods}

\section{Strains, growth conditions, and genetic crosses}

S. macrospora strains used in this study are given in Additional File 18: Table S3. Strains were grown in corn meal medium (BMM) or minimal medium (SWG) at 25

${ }^{\circ} \mathrm{C}$ as described $[109,110]$. S. macrospora is homothallic (self-fertile), and on BMM or SWG starts to form fruiting bodies at the medium/air interface after three days, maturation is reached after seven days [79]. For RNA extraction from total sexual mycelium for RNA-seq analysis, strains were grown as surface cultures in liquid SWG medium as described [28]. Mycelia harvested after the onset of sexual development contain developing fruiting bodies and the surrounding hyphae, these mycelia are referred to as sexual mycelium. Transformation protocols and protocols for genetic crosses for S. macrospora were as described previously $[46,111,112]$.

\section{Cloning procedures}

Plasmids for generating gene deletion strains, complementation experiments, fluorescence microscopy or protein interaction studies were cloned by homologous recombination in yeast as described [17]. Oligonucleotides used for generating PCR products for cloning procedures are given in Additional file 19: Table S4, plasmids are given in Additional file 20: Table S5. Deletion cassettes for pro44, $c r c 1$, and asm2 were generated by amplifying $1 \mathrm{~kb}$ genomic regions upstream and downstream of the corresponding genes, which were then cloned to flank the $h p h$ gene conferring hygromycin resistance [110]. Plasmid pRSnat-pro44-NA contains the pro44 open reading frame and $1.5 \mathrm{~kb}$ upstream and downstream regulatory regions including the $5^{\prime}$ and $3^{\prime}$ untranslated regions (UTRs, approximately 500 bp each), respectively, in pRSnat, which confers nourseothricin resistance in S. macrospora [113]. Plasmid pFA20 contains an $\mathrm{N}$-terminal fusion of the egfp gene to the pro44 gene under control of pro44 upstream and downstream regulatory regions $(1.5 \mathrm{~kb}$ each, including UTRs). Plasmid pFA30 contains an $\mathrm{N}$-terminal fusion of a TAP (tandem affinity purification)-tag $[114,115]$ to the pro44 gene under control of the Aspergillus nidulans gpd promoter and $\operatorname{trp} C$ terminator. Plasmids for yeast two-hybrid analysis containing three different splice variants of pro44 $(\mathrm{A}, \mathrm{B}, \mathrm{C})$ were generated by cloning pro $44 \mathrm{cDNAs}$ into yeast vectors pGADT7 and pGBKT7 (Clontech, Palo Alto, CA, USA). Plasmids containing C-terminal fusions of $e g f p$ to $c a c 2$, $c r c 1$, and $r t t 106$, respectively, were generated to express the fusion gene under control of the Aspergillus nidulans gpd promoter and $\operatorname{trpC}$ terminator. Plasmid pN_GFP-9436 for complementation of the asm2 deletion mutant contains an $\mathrm{N}$-terminal fusion of egfp to the asm2 gene under control of the asm 2 upstream and downstream regions ( $1.6 \mathrm{~kb}$ each, including UTRs).

\section{Generation of gene deletion strains}

Deletion strains for pro44, crc1, and asm2 were generated by transforming the deletion cassette (upstream and downstream regions flanking the $h p h$ gene, obtained by restriction digest of the corresponding gene deletion plasmid and gel elution) into a $\Delta \mathrm{ku} 70$ strain as described previously [116]. Hygromycin resistant primary transformants were verified for insertion of the deletion cassette 
by PCR and Southern blot analysis, and knockout strains were crossed against the spore color mutant fus [21] to obtain homokaryotic ascospore isolates carrying the deletion allele in a genetic background without the $\Delta \mathrm{ku} 70$ allele.

\section{Microscopy}

For microscopy of mycelia undergoing sexual development, S. macrospora strains were grown on glass slides with a thin layer of corn meal extract or corn meal medium solidified with $0.8 \%$ agar as described $[117,118]$. Fluorescence and light microscopic investigations were carried out with an AxioImager microscope (Zeiss, Jena, Germany). Fluorescence was studied using Chroma (Bellows Falls, VT, USA) filter set 41017 (HQ470/40, HQ525/ 50, Q495lp) for detection of EGFP, set 49008 (EG560/40x, ET630/75 m, T585lp) for the detection of tdTomato, and set 31000v2 (D350/50, D460/50, 400dclp) for the detection of DAPI and mKalama1. Images were captured with a Photometrix Cool SnapHQ camera (Roper Scientific) and MetaMorph (Universal Imaging). Recorded images were edited with MetaMorph and Adobe Photoshop CS4.

\section{Yeast two-hybrid analysis}

Screening of two yeast two-hybrid libraries and yeast two-hybrid analyses to test for interactions between selected proteins was done as described previously [42].

\section{Co-immunoprecipitation (co-IP)}

Strains carrying plasmid pFA30 (expressing TAP-tagged pro44) or pFA20 (expressing egfp-tagged pro44) were generated by transformation of $\Delta$ pro44. Fertile transformants were crossed to generate a strain carrying both plasmids. For Co-IP, strains were grown for $3 \mathrm{~d}$ at $25^{\circ} \mathrm{C}$ in $\mathrm{BMM}$ in petri dishes. Harvested, vacuum-dried mycelia were ground in liquid nitrogen. Mycelial powder was centrifuged in extraction buffer $(100 \mathrm{mM}$ Tris $\mathrm{pH} 7.6$, $250 \mathrm{mM} \mathrm{NaCl}, 2 \mathrm{mM}$ EDTA, 10\% Glycerin, 0.5\% NP-40) for $30 \mathrm{~min}$ at $4{ }^{\circ} \mathrm{C}$ and $13,500 \mathrm{rpm}$. Aliquots of the supernatant were used as protein extract for EGFP- or TAP-based immunoprecipitation. For EGFP-based immunoprecipitation (GFP-Trap), $30 \mu \mathrm{l}$ of GFP beads (ChromoTek GmbH, Planegg-Martinsried, Germany) were centrifuged three times $\left(1 \mathrm{~min}, 1000 \mathrm{rpm}, 4{ }^{\circ} \mathrm{C}\right.$ ) with $500 \mu \mathrm{l}$ dilution buffer $(10 \mathrm{mM}$ Tris, $\mathrm{pH} 7.5,150 \mathrm{mM}$ $\mathrm{NaCl}, 0.5 \mathrm{mM}$ EDTA, $1 \mathrm{mM}$ PMSF, $0.13 \mathrm{mM}$ benzamidine, $50 \mu \mathrm{l}$ protease inhibitor cocktail IV/25 ml). 500$600 \mu \mathrm{l}$ protein extract were added to the GFP beads and incubated for $2 \mathrm{~h}$ at $4{ }^{\circ} \mathrm{C}$ on a rotation device. Samples were centrifuged $\left(5 \mathrm{~min}, 5000 \mathrm{rpm}, 4^{\circ} \mathrm{C}\right.$ ), and the supernatant was removed. GFP beads were washed twice with $500 \mu \mathrm{l}$ dilution buffer. GFP beads were incubated with $80 \mu \mathrm{l} \mathrm{SDS}$ gel loading buffer for $5 \mathrm{~min}$ at $100^{\circ} \mathrm{C}$, and the samples were subsequently used for SDS page and
Western blotting and immunodetection with anti-GFP monoclonal antibody JL-8 (Clontech, Mountain View, CA, USA). For TAP-tag-based immunoprecipitation, $100 \mu \mathrm{l}$ IgG beads (GE Healthcare, Freiburg, Germany) were centrifuged $(1 \mathrm{~min} 1000 \mathrm{rpm})$ in $1 \mathrm{ml}$ TST buffer (50 mM Tris pH 7.6, $150 \mathrm{mM} \mathrm{NaCl}, 0.05 \%$ Tween 20). The supernatant was removed, and $500-600 \mu$ l protein extract was added to the beads. Beads were incubated for $3 \mathrm{~h}$ at $4{ }^{\circ} \mathrm{C}$ on a rotation device, and centrifuged for $1 \mathrm{~min}$ at $1000 \mathrm{rpm}$ and $4{ }^{\circ} \mathrm{C}$. Beads were washed twice for $10 \mathrm{~min}$ at $4{ }^{\circ} \mathrm{C}$ in $1 \mathrm{ml}$ IPP300 buffer $(25 \mathrm{mM}$ Tris pH 8, $300 \mathrm{mM} \mathrm{NaCl}, 0.1 \%(w / v)$ NP-40, $1 \mathrm{mM} \mathrm{PMSF}$, $0.13 \mathrm{mM}$ benzamidine, $2 \mathrm{mM}$ DTT, $50 \mu \mathrm{l}$ protease inhibitor cocktail IV/25 ml) and pelleted by centrifugation (1 min $1000 \mathrm{rpm}$ ). Beads were subsequently washed once in $1 \mathrm{ml}$ IPP150 buffer (25 mM Tris pH 8, $150 \mathrm{mM} \mathrm{NaCl}$, 0.1\% (w/v) NP-40, $1 \mathrm{mM}$ PMSF, $0.13 \mathrm{mM}$ benzamidine, $2 \mathrm{mM}$ DTT, $50 \mu \mathrm{l}$ protease inhibitor cocktail $\mathrm{IV} / 25 \mathrm{ml})$, and once in $1 \mathrm{ml}$ TEV CB buffer $(25 \mathrm{mM}$ Tris/ $\mathrm{HCl} \mathrm{pH} 8$, $150 \mathrm{mM} \mathrm{NaCl}, 0.1 \%$ NP-40, 0.5 mM EDTA, 1 mM DTT, $1 \mathrm{mM}$ PMSF). Pelleted beads were resuspended in $80 \mu \mathrm{l}$ SDS gel loading buffer, incubated for $5 \mathrm{~min}$ at $100{ }^{\circ} \mathrm{C}$, and the samples were subsequently used for SDS page and Western blotting and immunodetection with anti-Calmodulin Binding Protein Epitope Tag (Millipore, Darmstadt, Germany).

\section{Laser microdissection}

The $\Delta$ pro44 strain was grown for $4 \mathrm{~d}$ at $25^{\circ} \mathrm{C}$ on laser microdissection slides from MMI (Molecular Machines and Industries, Zürich, Switzerland), and protoperithecia were isolated with a CellCut Plus system as described [28]. RNA extraction and linear amplification from microdissected samples were as described [28] with the following modification: After addition of extraction buffer, protoperithecia were ground manually in a mortar to improve RNA yield by mechanic destruction of the cell walls. Success of grinding was verified microscopically before proceeding with the RNA extraction.

\section{RNA extraction and quantitative RT-PCR (RT-qPCR)}

Total RNA was prepared as described [119]. Reverse transcription and RT-qPCR were performed as described $[47,120]$, oligonucleotides used as primers are given in Additional file 19: Table S4. Primer efficiencies were calculated with LinRegPCR [121], and expression ratios were calculated with the $\Delta \Delta \mathrm{Ct}$ method [122]. The $\mathrm{Ct}$ values for an amplicon derived from the SSU rRNA were used as a reference for normalization. Tests for statistical significance were performed with REST [123].

\section{RNA-seq analysis}

RNA-seq analysis of total sexual RNA from the wild type, $\Delta$ asf1, and $\Delta$ pro44, as well as amplified RNA from 
laser microdissected protoperithecia of $\Delta$ pro44 was done as described previously [28]. For total RNA extraction, strains were grown for $4 \mathrm{~d}$ in SWG medium as surface cultures to induce sexual development and allow protoperithecia formation. Mutant strains $\Delta$ asf1 and $\Delta$ pro44 have reached their developmental block by this time. Library preparation and sequencing was done at GATC Biotech (Konstanz, Germany). Single reads of 51 nucleotides were obtained for each sample on an Illumina HiSeq2500. For each strain/condition, two independent biological replicates were sequenced. Analysis of RNA-seq data was done as described previously with minor modifications [28]. Briefly, reads were trimmed with custom-made Perl programs to remove reads with nondetermined nucleotides, remove polyA or poly $\mathrm{T}$ stretches from end and start of reads, respectively, and trim reads from $3^{\prime}$ and $5^{\prime}$ ends until a base quality of $\geq 10$ was reached. Trimmed reads $\geq 40$ bases were kept for mapping to the $S$. macrospora genome using Tophat v2.2.1 [124, 125]. Reads mapping to annotated features were counted as described [28], and quantitative analysis of gene expression was performed with DESeq2 and LOX [126, 127]. Results of expression analyses for all S. macrospora genes are given in Additional file 9: Table S1.

\section{Micrococcal nuclease sequencing (MNase-seq)}

For MNase-seq of the wild type and $\Delta$ asf1, strains were grown for $3 \mathrm{~d}$ in SWG medium as surface cultures. Mycelia were harvested, ground in liquid nitrogen, and suspended in $1 \mathrm{ml}$ MNase buffer $(5 \mathrm{mM} \mathrm{CaCl}, 50 \mathrm{ml}$ Tris- $\mathrm{HCl}, \mathrm{pH} 8)$ per $100 \mathrm{mg}$ mycelium. $200 \mu \mathrm{l}$ of resuspended mycelium were treated with 30 units MNase (Thermo Fisher, Waltham, MA, USA) for $10 \mathrm{~min}$ at $37{ }^{\circ} \mathrm{C}$ with shaking ( $400 \mathrm{rpm})$. Samples were centrifuged for 15 min at $15000 \mathrm{rpm}$, the supernatant was subjected to one round of phenol/chloroform extraction, and treated for $15 \mathrm{~min}$ at $37^{\circ} \mathrm{C}$ with $10 \mu \mathrm{l}$ RNase cocktail enzyme mix (Thermo Fisher, Waltham, MA, USA). After another phenol/chloroform extraction step, DNA was precipitated with ethanol, washed and resuspended in $30 \mu \mathrm{l}$ distilled water. MNase digestion was verified by agarose gel electrophoresis. Library preparation and sequencing was done at GATC Biotech (Konstanz, Germany). Single or paired-end reads were obtained for each sample on an Illumina HiSeq2500. For each strain, two independent biological replicates were sequenced. Reads were trimmed as described [25], and mapped to the $S$. macrospora genome [21, 124] using Bowtie2 v2.2.6 [128]. Resulting .bam files were converted to bed format with BEDTools [129], and nucleosome positions were determined with iNPS v1.2.2 [130]. Further processing of results and analysis of nucleosome distributions around transcriptional start sites
(TSS) was done with custom-made Perl scripts using BioPerl [131].

\section{Bisulfite sequencing (BS-seq)}

For BS-seq of the wild type and $\Delta$ asf1, strains were grown for $4 \mathrm{~d}$ in SWG medium as surface cultures. Mycelia were harvested, ground in liquid nitrogen, and suspended in $500 \mu \mathrm{l}$ lysis buffer $(0.6 \mathrm{M} \mathrm{NaCl}, 10 \mathrm{mM}$ EDTA, $1 \%$ SDS, $100 \mathrm{mM}$ Tris- $\mathrm{HCl} \mathrm{pH} 8.0)$ and $500 \mu \mathrm{l}$ phenol/ chloroform. Samples were subjected to one to two rounds of phenol/chloroform extraction, treated for 60 min at $37^{\circ} \mathrm{C}$ with $10 \mu \mathrm{l}$ RNase cocktail enzyme mix (Thermo Fisher, Waltham, MA, USA), and treated again with phenol/chloroform extraction. The supernatant was cleaned three times on Amicon Ultra $30 \mathrm{k}$ columns (Merck, Darmstadt, Germany) with elution buffer (10 $\mathrm{mM}$ Tris- $\mathrm{HCl} \mathrm{pH} 8.0$ ) and eluted in $100 \mu \mathrm{l}$ of elution buffer. Bisulfite treatment, preparation of a directional library, and sequencing on an Illumina HiSeq were performed at GATC Biotech AG (Konstanz, Germany). Bisulfite conversion rates based on the analysis of the mitochondrial DNA for wild type and $\Delta$ asf1 were 99.0 and $99.3 \%$, respectively, in the first experiment, and 99.4 and $99.1 \%$, respectively, in the second experiment. Reads were trimmed for low quality bases and adapter removal with Trimmomatic [132] (parameters ILLUMINACLIP:TruSeq3-PE-2.fa:2:30:10:1:TRUE LEADING:3 TRAILING:3 SLIDINGWINDOW:4:15 MINLEN:40). Trimmed reads were mapped to the $S$. macrospora genome and methylated cytosines identified using Bismark [133]. After mapping, reads were deduplicated, and methylated cytosines identified with the Bismark methylation extractor (parameters --ignore_r2 2 --no_overlap). Only cytosines that were methylated in at least $5 \%$ of mapped reads were counted as positions where methylation occurred. Further processing of results and analysis of methylation in annotated features (genes, upstream regions and repeat regions) was done with custom-made Perl scripts using BioPerl [131].

\section{Additional files}

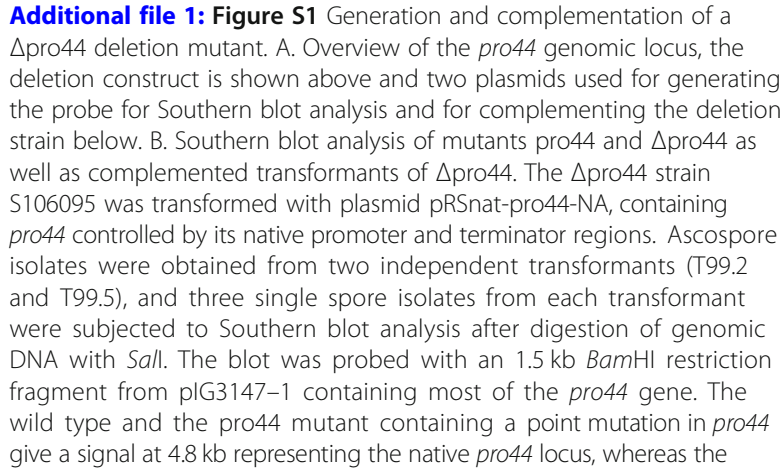
$\triangle$ pro44 deletion mutant. A. Overview of the pro44 genomic locus, the deletion construct is shown above and two plasmids used for generating the probe for Southern blot analysis and for complementing the deletion strain below. B. Southern blot analysis of mutants pro44 and $\Delta$ pro44 as well as complemented transformants of $\Delta$ pro44. The $\Delta$ pro44 strain S106095 was transformed with plasmid pRSnat-pro44-NA, containing pro44 controlled by its native promoter and terminator regions. Ascospore isolates were obtained from two independent transformants (T99.2 and T99.5), and three single spore isolates from each transformant were subjected to Southern blot analysis after digestion of genomic DNA with Sall. The blot was probed with an $1.5 \mathrm{~kb}$ BamHI restriction fragment from plG3147-1 containing most of the pro44 gene. The wild type and the pro44 mutant containing a point mutation in pro44 give a signal at $4.8 \mathrm{~kb}$ representing the native pro 44 locus, whereas the 
deletion mutant does not give a signal as expected. Complemented transformants give a signal at $3.2 \mathrm{~kb}$ representing an internal fragment of the native pro44 locus used for complementation and one or more additional bands indicating at least one plasmid integration event. C. Complementation of $\Delta$ pro 44 . Mutant $\Delta$ pro 44 was transformed with plasmid pRSnatpro44-NA (transformant S108950, Dpro44::SMAC_03223_native). The region of the agar/air interface of longitudinal sections from cultures of the wild type, the sterile mutant pro 44 , the deletion strain $\triangle$ pro 44 and a complemented transformant of the knockout is shown. The wild type forms perithecia at the surface of the growth medium, while mutants pro44 and $\Delta$ pro44 only form protoperithecia that are submerged in the agar (white arrowheads point to examples). Complemented transformants are able to produce perithecia at the agar surface like the wild type; however, some protoperithecia and even perithecia are still formed submerged in the medium. (PDF $6507 \mathrm{~kb}$ )

Additional file 2: Figure S2. Co-immunoprecipitation of strain S198 expressing only egfp-pro44, but not ntap-pro44. TAP-tag-based immunoprecipitation was performed and the isolated proteins were analyzed by Western blot with an anti-GFP antibody. The part of the Western blot shown in Fig. 2 is labelled in red. Crude extract from the wild type as well as a result from a co-immunoprecipitation of strain $\$ 135826$ expressing egfp-pro44 and ntap-pro44 were used as negative and positive controls, respectively. The unspecific band (green asterisk) seen in the region labelled in red (and in the wild type crude extract, green asterisk) is slightly lower than the EGFP-PRO44 protein detected in the co-IP of strain $\mathrm{S} 135826$ (blue asterisk). The Fig. shows a long exposure of the Western Blot detection to better visualize the unspecific bands. (PDF $214 \mathrm{~kb}$ )

Additional file 3: Figure S3. Southern blot analysis of $\Delta \mathrm{cac} 2, \Delta \mathrm{rtt} 106$ double mutants. A. Overview of the cac2 and rtt106 genomic loci in the wild type and the corresponding deletion mutants, with the probes for the Southern blot indicated. B. Strains $\Delta r t t 106$, fus and $\Delta c a c 2$ were crossed and single ascospore isolates were obtained. Three single spore isolates were subjected to Southern blot analysis after digestion of genomic DNA with the indicated enzymes. The blots were probed with the indicated probes. The resulting signals are as expected for the single and double mutants. Triangles indicate the weak bands in two cases, the asterisks in the blot probed with the rtt106 deletion cassette indicate undigested high molecular weight DNA. (PDF $1231 \mathrm{~kb}$ )

Additional file 4: Figure S4. Southern blot analysis of $\Delta \mathrm{crc} 1$ strains. A. Overview of the crcl genomic locus in the wild type and the corresponding deletion mutant, with the probes for the Southern blot indicated. B. Southern blot analysis of the wild type, one primary transformant (T124.1) and nine single spore isolates of two different independent primary transformants after digestion of genomic DNA with the indicated enzymes. The blots were probed with the indicated probes. The resulting signals are as expected for the $\mathrm{crcl}$ deletion for strains T124.1, S123582, S123587, S123615, S123617, S123635, S123637, and S123704 (6.8 kb band when probed with the deletion cassette, and no signal when probed with the gene-specific probe, whereas the wild type and non-deletion-carrying transformants give bands of 3.7 and $4.6 \mathrm{~kb}$ when probed with the deletion cassette, and a $8.2 \mathrm{~kb}$ band with the gene-specific probe). Deletion strains that were used in further experiments are labelled in red. (PDF $1362 \mathrm{~kb}$ )

Additional file 5: Figure S5. Southern blot analysis of $\Delta \mathrm{crc} 1$ double mutants. A. Overview of the genomic locus in the different deletion mutants, with the probe for the Southern blot indicated. b. Southern blot analysis of the wild type and the $\Delta \mathrm{crc1}, \Delta \mathrm{rtt} 106$ double mutant $\mathrm{S} 126403$ after digestion of genomic DNA with Hindlll. The blot was probed with the hph cassette. The resulting signals are as expected for the double mutant $(6.8 \mathrm{~kb}$ band for the $\Delta \mathrm{crc} 1$ locus and $3.7 \mathrm{~kb}$ band for the $\Delta \mathrm{rtt} 106$ locus) and the wild type (no signal). C. Southern blot analysis of the wild type and single ascospore isolates from crosses of $\Delta \mathrm{crc1}$ and $\Delta \mathrm{asf1}$, or $\Delta \mathrm{crc1}$ and $\Delta \mathrm{cac} 2$, respectively. Genomic DNA was digested with Hindlll. The blot was probed with the $h p h$ cassette. Double mutants $\Delta$ crc1, $\Delta$ asf1 can be identified by bands at $6.8 \mathrm{~kb}$ for the $\Delta \mathrm{crc} 1$ deletion and $3.5 \mathrm{~kb}$ band for the $\Delta a s f 1$ deletion. Double mutants $\Delta \mathrm{crc} 1, \Delta \mathrm{cac} 2$ can be identified by bands at $6.8 \mathrm{~kb}$ for the $\Delta \mathrm{crc} 1$ deletion and $4.2 \mathrm{~kb}$ band for the $\Delta \mathrm{cac} 2$ deletion. Double deletion strains that were used in further experiments are labelled in red. (PDF $1061 \mathrm{~kb}$ )
Additional file 6: Figure S6. Phylogenetic analysis of CRC subunitcontainig proteins in ascomycetes. Protein sequences were aligned with Clustal X, and a Neighbor Joining analysis was performed with PAUP* with 1000 bootstrap replicates (bootstrap percentages are given at the branches). Sequences from the following ascomycetes were used for analysis with the CRC-subunit protein CC1G_08669 from the basidiomycete Coprinopsis cinerea (CC1G) as an outgroup: Aspergillus nidulans (ANID), Neurospora crassa (NCU), Pyronema confluens (PCON), Saccharomyces cerevisiae (S.c.), Schizosaccharomyces pombe (S.p.), Sclerotinia sclerotiorum (SS1G), Sordaria macrospora (SMAC), Stagonospora nodorum (SNOT), Tuber melanosporum (GSTUMT). The S. macrospora CRC1 protein is part of a cluster of proteins on a separate branch from the cluster containing the $S$. cerevisiae and $S$. pombe Rsc7 proteins. (PDF $131 \mathrm{~kb}$ )

Additional file 7: Figure S7. Analysis of subcellular localization of RTT106, CAC2, and CRC1 by fluorescence microscopy. A. Nuclear localization of RTT106 and CAC2. Both genes were fused with egfp and co-transformed with plasmid $\mathrm{pRH} 2 \mathrm{~B}$ expressing a tdTomato-labelled histone. RTT106 and CAC2 co-localize with the histone in the nucleus. Growth $2 \mathrm{~d}$ on slides with BMM, scale bar $20 \mu \mathrm{m}$. pRH2B contains genes for histone H2B fused with tdTomato (Teichert et al. 2014, PLoS Genet. 10:e1004582). B. Nuclear localization of CRC1. crcl fused with egfp and expressed from plasmid pSMAC_02795_EGFP. CRC1 co-localizes with the DAPI-labelled nuclei. Growth 2d on slides with BMM, scale bar $10 \mu \mathrm{m}$. (PDF $3836 \mathrm{~kb}$ )

Additional file 8: Figure S8. Fruiting body development in chromatin modifier mutants. A. Strains were grown for $7 \mathrm{~d}$ on BMM at $25^{\circ} \mathrm{C}$. Photographs show fruiting body development on petri dishes, small boxes in lower left of each picture show enlarged sections of each overview. Scale bar in small boxes is $2 \mathrm{~mm}$. B. Strains were grown for $7 \mathrm{~d}$ on SWG at $25^{\circ} \mathrm{C}$. Photographs show fruiting body development on petri dishes. (PDF $5774 \mathrm{~kb}$ )

Additional file 9: Table S1. RNA-seq analysis of S. macrospora wild type and mutant strains. (XLSX $8905 \mathrm{~kb})$

Additional file 10: Figure S9. Heatmap of Spearman's correlation coefficients for pairwise comparisons of the sets of RPKM values ( $\log _{2}$ transformed) for each analyzed RNA-seq sample (two independent biological replicates per strain/condition). Included were RPKM values for all genes that had a measurement in all samples. Clustering and heatmap generation were done in R. (PDF $161 \mathrm{~kb}$ )

Additional file 11: Figure S10. Expression of pks and nrps genes in different mutants and tissues. A. Heatmap was generated based on the $\log 2$ ratios from the DESeq2 analysis of RNA-seq data. Two pks genes that were previously shown to be involved in fruiting body formation (pks4 for fruiting body formation and morphology, pks7 for melanin formation for black pigmentation of perithecia and ascospores) are given in bold. The results show that $p k s 4$ is indeed upregulated in $\Delta$ asf1, but not $\Delta$ pro44 mycelium. Furthermore it is upregulated in all protoperithecia samples compared to wild type, again showing that expression is not strongly dependent on pro44, pro1, or nox1. Overall, several pks and nrps genes are upregulated in $\triangle$ asf1 mycelia, more than in $\Delta$ pro44 mycelia, and about half of the genes are strongly upregulated in wild type protoperithecia. B. Expression of $p k s 4$ in transcription factor or chromatin modifier mutants. Quantitative RT-PCR analysis of pks4 expression was performed, ratios and standard errors (given as error bars) were calculated with REST. Dots indicate significantly differential expression (REST, $p<=0.05$ ). Data for pro1 and pro44 are from Schindler and Nowrousian 2014 (Fungal Genet Biol 68: 48-59). (PDF 199 kb)

Additional file 12: Figure S11. Distances between nucleosome pairs as determined by iNPS analysis of MNase-seq reads of wild type and $\Delta$ asf1. Results are shown for two independent biological replicates for each strain. A. Analyzed were distances between pairs of nucleosomes of the iNPS category "MainPeak". B. Analyzed were all nucleosome pair distances, irrespective of nucleosome type determined by iNPS (nucleosome types MainPeak, MainPeak:doublet, MainPeak+Shoulder, Shoulder). (PDF $157 \mathrm{~kb}$ )

Additional file 13: Table S2. Bisulfite sequencing (BS-seq) of the wild type and the asf1 mutant. (XLSX $1770 \mathrm{~kb})$ 
Additional file 14: Figure S12. Expression of carbonic anhydrase genes of S. macrospora in different mutants/conditions. Hierarchical clustering and heatmap generation of the log2 of fold ratios as determined in the DESeq2 analysis were done in R. (PDF $162 \mathrm{~kb}$ )

Additional file 15: Figure S13. Multiple alignment of SMAC_09436 (ASM2) orthologs. Orthologs were determined by bidirectional BLASTP analyses. Proteins from the Sordariomycetes Sordaria macrospora (S.m., SMAC_09436), Neurospora crassa (N.c., NCU010258), Podospora anserina (P.a., CDP26737.1), Magnaporthe oryzae (M.o., XP_003720415.1), Fusarium graminearum (F.g., FGRAMPH1_01T14721), and Trichoderma reesei (T.r., XP_006961730.1) were aligned with ClustalX. No clear orthologs outside of the Sordariomycetes could be identified. The GAL4 (GAL4-like Zn2Cys6 binuclear cluster DNA-binding) domain and the fungal_TF_MHR (fungal transcription factor regulatory middle homology region) domain in SMAC_09436 are indicated by black and grey bars, respectively, above the sequence. (PDF $176 \mathrm{~kb}$ )

Additional file 16: Figure S14. Southern blot/PCR analysis of $\triangle a s m 2$ ( $\left.\triangle S M A C \_09436\right)$ strains and complemented transformants. A. Overview of the asm2 genomic locus in the wild type and the corresponding deletion mutant, with the probes for the Southern blot indicated. Below, the SMAC_09436-containing region of complementation vector pN_GFP-9436 is shown. Blue and yellow arrows indicate primers for PCRs described in C. B. Southern blot analysis of the wild type and ten single spore isolates after digestion of genomic DNA with Pstl. The blots were probed with the indicated probes. The resulting signals are as expected for both probes (sizes indicated below the blots). Deletion strains that were used in further experiments are labelled in red. C. Ectopic integration of complementation plasmid pN_GFP-9436 was confirmed by PCR. Six different single spore isolates from two different complemented transformants were analyzed with two different primer sets (see A). Spore isolates RL726 and RL740 are based on deletion strain S148783 as recipient for transformation, spore isolates RL754, RL756, RL760, and RL775 are based on S148694. As expected, with the primers amplifying a fragment from egfp to the asm2 promoter region (yellow arrows in A), amplicons were obtained only with the complemented transformants and the plasmid control. With primers amplifying a fragment from the C-terminal region to the terminator region of asm2, only complemented transformants, the wild type, and the plasmid control gave amplicons as expected. (PDF $1498 \mathrm{~kb}$ )

Additional file 17: Figure S15. Morphological characterization of

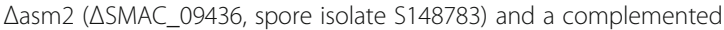
transformant (spore isolate RL726). Strains were grown on full medium (BMM) or defined medium (SWG) at $25^{\circ} \mathrm{C}$ for the indicated times. Scale bars are the same for all overview (left column for each time point, top view of perithecia growing on the surface of the agar medium) and detail (right column for each time point, side view of perithecia growing on the surface of the agar medium) pictures. In the asm2 deletion strain as well as the complemented transformant, perithecia are sometimes not arranged perpendicular to the growth surface as in the wild type (red arrows). (PDF $5730 \mathrm{~kb}$ )

Additional file 18: Table S3. Sordaria macrospora strains used in this study. (PDF $288 \mathrm{~kb}$ )

Additional file 19: Table S4. Oligonucleotides used in this study. (PDF $318 \mathrm{~kb}$ )

Additional file 20: Table S5. Plasmids used in this study. (PDF $270 \mathrm{~kb}$ )

\section{Acknowledgements}

The authors would like to thank Swenja Ellßel, Ingeborg Godehardt, and Silke Nimtz for excellent technical assistance.

\section{Funding}

This work was funded by the German Research Foundation (DFG) with grants to UK (KU517/16-1) and MN (NO407/5-1). We acknowledge support by the DFG Open Access Publication Funds of the Ruhr-Universität Bochum. The funders had no role in study design, data collection and analysis, decision to publish, or preparation of the manuscript.

\section{Availability of data and materials}

Sequencing data generated in this study were submitted to the GEO database, accession numbers are GSE92337 (RNA-seq data), GSE92461 (MNase-seq data), and GSE114029 (BS-seq data). RNA-seq data for protoperithecia from the wild type and mutants pro1 and $\triangle$ nox 1 were generated previously $[28,46]$ and are available under GEO accession numbers GSE33668 and GSE49363.

\section{Authors' contributions}

MN conceptualized the study, DIS, FA, IT, RL, and MN performed the investigations, DIS and MN performed formal analysis, MN and UK acquired funding for the study, MN wrote the manuscript, DIS, FA, RL, and MN prepared Figures and Tables, all authors read and edited the manuscript. All authors read and approved the final manuscript.

Ethics approval and consent to participate

Not applicable.

\section{Consent for publication}

Not applicable.

Competing interests

The authors declare that they have no competing interests.

\section{Publisher's Note}

Springer Nature remains neutral with regard to jurisdictional claims in published maps and institutional affiliations.

\section{Author details}

'Lehrstuhl für Allgemeine und Molekulare Botanik, Ruhr-Universität Bochum, 44780 Bochum, Germany. ${ }^{2}$ LOEWE-Zentrum für Synthetische Mikrobiologie \& Department of Chemistry, Philipps University of Marburg, Marburg, Germany.

Received: 25 September 2018 Accepted: 28 November 2018 Published online: 13 December 2018

\section{References}

1. Knoll AH. The multiple origins of complex multicellularity. Annu Rev Earth Planet Sci. 2011;39:217-39.

2. Niklas KJ. The evolutionary-developmental origins of multicellularity. Am J Bot. 2014;101:6-25.

3. Nagy LG. Evolution: Complex multicellular life with 5,500 genes. Curr Biol. 2017;27:R609-R10

4. Nagy LG, Kovács GM, Krizsán K. Complex multicellularity in fungi: evolutionary convergence, single origin, or both. Biol Rev. 2018;in press. https://doi.org/10.1111/brv.12418.

5. Dyer PS, O'Gorman CM. Sexual development and cryptic sexuality in fungi: insights from aspergillus species. FEMS Microbiol Rev. 2012;36:165-92.

6. Nowrousian M. Genomics and transcriptomics to study fruiting body development: an update. Fungal Biol Rev. 2018;in press. https://doi.org/10. 1016/j.fbr.2018.02.004

7. Pöggeler S, Nowrousian M, Teichert I, Beier A, Kück U. Fruiting body development in ascomycetes. In: Anke T, Schüffler A, editors. The Mycota XV, physiology and genetics. 2nd ed. Berlin-Heidelberg: Springer; 2018.

8. Bistis GN, Perkins DD, Read ND. Different cell types in Neurospora crassa. Fungal Genet Newsl. 2003;50:17-9.

9. Han KH. Molecular genetics of Emericella nidulans sexual development. Mycobiology. 2009;37:171-82.

10. Lord KM, Read ND. Perithecium morphogenesis in Sordaria macrospora. Fungal Genet Biol. 2011;49:388-99.

11. Nowrousian M. Genomics and transcriptomics to analyze fruiting body development. In: Nowrousian M, editor. The Mycota XIII fungal genomics 2nd. 2nd ed. Berlin, Heidelberg: Springer; 2014. p. 149-72.

12. Debuchy R, Turgeon BG. Mating-type structure, evolution, and function in Euascomycetes. In: Kües U, Fischer R, editors. The Mycota I: growth, differentiation and sexuality. Berlin, Heidelberg: Springer-Verlag; 2006. p. 293-323.

13. Dyer PS, Kück U. Sex and the imperfect fungi. Microbiol Spectr. 2017:5. https://doi.org/10.1128/microbiolspec.FUNK-0043-2017. 
14. Gerke J, Braus GH. Manipulation of fungal development as source of nove secondary metabolites for biotechnology. Appl Microbiol Biotechnol. 2014 98:8443-55.

15. Masloff S, Pöggeler S, Kück U. The pro1+ gene from Sordaria macrospora encodes a $\mathrm{C}_{6}$ zinc finger transcription factor required for fruiting body development. Genetics. 1999;152(1):191-9.

16. Steffens EK, Becker K, Krevet S, Teichert I, Kück U. Transcription factor PRO1 targets genes encoding conserved components of fungal developmental signaling pathways. Mol Microbiol. 2016;102:792-809.

17. Colot HV, Park G, Turner GE, Ringelberg C, Crew CM, Litvinkova L, et al. A high-throughput gene knockout procedure for Neurospora reveals functions for multiple transcription factors. Proc Natl Acad Sci U S A. 2006;103:10352-7.

18. Sun $Q$, Choi GH, Nuss DL. Hypovirus-responsive transcription factor gene prol of the chestnut blight fungus Cryphonectria parasitica is required for female fertility, asexual spore development, and stable maintenance of hypovirus infection. Eukaryot Cell. 2009;8:262-70

19. Vienken $K$, Fischer $R$. The Zn(II)2Cys6 putative transcription factor NosA controls fruiting body formation in Aspergillus nidulans. Mol Microbiol. 2006;61(2):544-54.

20. Han KH, Han KY, Yu JH, Chae KS, Jahng KY, Han DM. The nsdD gene encodes a putative GATA-type transcription factor necessary for sexual development of Aspergillus nidulans. Mol Microbiol. 2001:41:299-309.

21. Nowrousian M, Teichert I, Masloff S, Kück U. Whole-genome sequencing of Sordaria macrospora mutants identifies developmental genes. G3 (Bethesda). 2012;2:261-70.

22. Schumacher J, Simon A, Cohrs KC, Viaud M, Tudzynski P. The transcription factor BCLTF1 regulates virulence and light responses in the necrotrophic plant pathogen Botrytis cinerea. PLoS Genet. 2014;10:e1004040.

23. Szewczyk E, Krappmann S. Conserved regulators of mating are essential for Aspergillus fumigatus cleistothecium formation. Eukaryot Cell. 2010;9:774-83.

24. Bazafkan H, Beier S, Stappler E, Böhmdorfer S, Oberlerchner JT, Sulyok M, et al. SUB1 has photoreceptor dependent and independent functions in sexual development and secondary metabolism in Trichoderma reesei. Mol Microbiol. 2017;106:742-59.

25. Traeger S, Altegoer F, Freitag M, Gabaldon T, Kempken F, Kumar A, et al. The genome and development-dependent transcriptomes of Pyronema confluens: a window into fungal evolution. PLoS Genet. 2013;9:e1003820.

26. Sancar C, Ha N, Yilmaz R, Tesorero R, Fisher T, Brunner M, et al. Combinatorial control of light induced chromatin remodeling and gene activation in Neurospora. PLoS Genet. 2015;11:e1005105.

27. Chen CH, Ringelberg CS, Gross RH, Dunlap JC, Loros JJ. Genome-wide analysis of light-inducible responses reveals hierarchical light signalling in Neurospora. EMBO J. 2009;28:1029-42.

28. Teichert I, Wolff G, Kück U, Nowrousian M. Combining laser microdissection and RNA-seq to chart the transcriptional landscape of fungal development. BMC Genomics. 2012;13:511.

29. Freitag M. Fungal chromatin and its role in regulation of gene expression. In: Nowrousian M, editor. The Mycota XIII fungal genomics 2nd Edition. 2nd ed. Berlin, Heidelberg: Springer; 2014. p. 99-120.

30. Voss TC, Hager GL. Dynamic regulation of transcriptional states by chromatin and transcription factors. Nat Rev Genet. 2014;15:69-81.

31. Zhang Z, Pugh BF. High-resolution genome-wide mapping of the primary structure of chromatin. Cell. 2011;144:175-86.

32. Rountree MR, Selker EU. DNA methylation and the formation of heterochromatin in Neurospora crassa. Heredity (Edinb). 2010;105:38-44.

33. Ding S, Mehrabi R, Koten C, Kang Z, Wei Y, Seong K, et al. Transducin betalike gene FTL1 is essential for pathogenesis in Fusarium graminearum. Eukaryot Cell. 2009:8:867-76.

34. Li Y, Wang C, Liu W, Wang G, Kang Z, Kistler HC, et al. The HDF1 histone deacetylase gene is important for conidiation, sexual reproduction, and pathogenesis in Fusarium graminearum. Mol Plant Microbe Interact. 2011;24: 487-96.

35. Ramamoorthy V, Shantappa S, Dhingra S, Calvo AM. veA-dependent RNApol II transcription elongation factor-like protein, RtfA, is associated with secondary metabolism and morphological development in Aspergillus nidulans. Mol Microbiol. 2012;85:795-814.

36. Sarikaya-Bayram O, Bayram O, Feussner K, Kim JH, Kim HS, Kaever A, et al. Membrane-bound methyltransferase complex VapA-VipC-VapB guides epigenetic control of fungal development. Dev Cell. 2014;29:406-20.

37. Gesing S, Schindler D, Fränzel B, Wolters D, Nowrousian M. The histone chaperone ASF1 is essential for sexual development in the filamentous fungus Sordaria macrospora. Mol Microbiol. 2012;84:748-65.
38. Hammond CM, Strømme CB, Huang H, Patel DJ, Groth A. Histone chaperone networks shaping chromatin function. Nat Rev Mol Cell Biol. 2017;18:141-58

39. Das C, Tyler JK, Churchill ME. The histone shuffle: histone chaperones in an energetic dance. Trends Biochem Sci. 2010;35:476-89.

40. Mousson F, Ochsenbein F, Mann C. The histone chaperone Asf1 at the crossroads of chromatin and DNA checkpoint pathways. Chromosoma. 2007;116:79-93.

41. Zhu Y, Weng M, Yang Y, Zhang C, Li Z, Shen WH, et al. Arabidopsis homologues of the histone chaperone ASF1 are crucial for chromatin replication and cell proliferation in plant development. Plant J. 2011;66:443-55.

42. Teichert I, Steffens EK, Schnaß N, Fränzel B, Krisp C, Wolters DA, et al. PRO40 is a scaffold protein of the cell wall integrity pathway, linking the MAP kinase module to the upstream activator protein kinase C. PLOS Genet. 2014;10:e1004582

43. Kelley LA, Mezulis S, Yates CM, Wass MN, Sternberg MJ. The Phyre2 web portal for protein modeling, prediction and analysis. Nat Protoc. 2015;10: 845-58.

44. Wilson B, Erdjument-Bromage $H$, Tempst $P$, Cairns BR. The RSC chromatin remodeling complex bears an essential fungal-specific protein module with broad functional roles. Genetics. 2006:172:795-809.

45. Lorch Y, Kornberg RD. Chromatin-remodeling for transcription. Q Rev Biophys. 2017:50:e5.

46. Dirschnabel DE, Nowrousian M, Cano-Domínguez N, Aguirre J, Teichert I, Kück U. New insights into the roles of NADPH oxidases in sexual development and ascospore germination in Sordaria macrospora. Genetics. 2014;196:729-44.

47. Schindler D, Nowrousian M. The polyketide synthase gene pks4 is essential for sexual development and regulates fruiting body morphology in Sordaria macrospora. Fungal Genet Biol. 2014;68:48-59.

48. Engh I, Nowrousian M, Kück U. Regulation of melanin biosynthesis via the dihydroxynaphtalene pathway is dependent on sexual development in the ascomycete Sordaria macrospora. FEMS Microbiol Lett. 2007;275:62-70.

49. Voong LN, Xi L, Wang JP, Wang X. Genome-wide mapping of the nucleosome landscape by micrococcal nuclease and chemical mapping. Trends Genet. 2017. https://doi.org/10.1016/j.tig.2017.05.007.

50. lyer VR. Nucleosome positioning: bringing order to the eukaryotic genome. Trends Cell Biol. 2012;22:250-6.

51. Becker JM, Yau C, Hancock JM, Holmes CC. NucleoFinder: a statistical approach for the detection of nucleosome positions. Bioinformatics. 2013: 29:711-6.

52. Kaplan N, Moore IK, Fondufe-Mittendorf Y, Gossett AJ, Tillo D, Field Y, et al. The DNA-encoded nucleosome organization of a eukaryotic genome. Nature. 2009:458(7236):362-6.

53. Mavrich TN, Jiang C, loshikhes IP, Li X, Venters BJ, Zanton SJ, et al. Nucleosome organization in the Drosophila genome. Nature. 2008; 453(7193):358-62

54. Schones DE, Cui K, Cuddapah S, Roh TY, Barski A, Wang Z, et al. Dynamic regulation of nucleosome positioning in the human genome. Cell. 2008;132: 887-98

55. Weiner A, Hughes A, Yassour M, Rando OJ, Friedman N. High-resolution nucleosome mapping reveals transcription-dependent promoter packaging. Genome Res. 2010;20(1):90-100.

56. Lin LJ, Schultz MC. Promoter regulation by distinct mechanisms of functional interplay between lysine acetylase Rtt109 and histone chaperone Asf1. Proc Natl Acad Sci U S A. 2011;108:19599-604.

57. Rufiange A, Jacques PE, Bhat W, Robert F, Nourani A. Genome-wide replicationindependent histone $\mathrm{H} 3$ exchange occurs predominantly at promoters and implicates H3 K56 acetylation and Asf1. Mol Cell. 2007;27:393-405.

58. Kouzminova E, Selker EU. dim-2 encodes a DNA methyltransferase responsible for all known cytosine methylation in Neurospora. EMBO J. 2001:20:4309-23.

59. Tamaru H, Selker EU. A histone $\mathrm{H} 3$ methyltransferase controls DNA methylation in Neurospora crassa. Nature. 2001:414:277-83.

60. Krueger F, Kreck B, Franke A, Andrews SR. DNA methylome analysis using short bisulfite sequencing data. Nat Methods. 2012;9:145-51.

61. Wreczycka K, Gosdschan A, Yusuf D, Grüning B, Assenov Y, Akalin A. Strategies for analyzing bisulfite sequencing data. J Biotechnol. 2017;261: 105-15.

62. Zemach AMI, Silva P, Zilberman D. Genome-wide evolutionary analysis of eukaryotic DNA methylation. Science. 2010;328:916-9. 
63. Aramayo R, Selker EU. Neurospora crassa, a model system for epigenetics research. Cold Spring Harb Perspect Biol. 2013;5:a017921.

64. Montanini B, Chen PY, Morselli M, Jaroszewicz A, Lopez D, Martin F, et al. Non-exhaustive DNA methylation-mediated transposon silencing in the black truffle genome, a complex fungal genome with massive repeat element content. Genome Biol. 2014;15:411.

65. Priebe S, Kreisel C, Horn F, Guthke R, Linde J. FungiFun2: a comprehensive online resource for systematic analysis of gene lists from fungal species. Bioinformatics. 2015;31:445-6.

66. Ruepp A, Zollner A, Maier D, Albermann K, Hani J, Mokrejs M, et al. The FunCat, a functional annotation scheme for systematic classification of proteins from whole genomes. Nucl Acids Res. 2004;32:5539-45.

67. Elleuche S, Pöggeler S. Evolution of carbonic anhydrases in fungi. Curr Genet. 2009;55:211-22.

68. Elleuche S, Pöggeler S. Carbonic anhydrases in fungi. Microbiology. 2010; 156:23-9.

69. Bahn YS, Mühlschlegel FA. $\mathrm{CO}_{2}$ sensing in fungi and beyond. Curr Opin Microbiol. 2006;9:572-8.

70. Elleuche S, Pöggeler S. $\beta$-Carbonic anhydrases play a role in fruiting body development and ascospore germination in the filamentous fungus Sordaria macrospora. PLoS One. 2009;4:e5177.

71. Lehneck R, Elleuche S, Pöggeler S. The filamentous ascomycete Sordaria macrospora can survive in ambient air without carbonic anhydrases. Mol Microbiol. 2014;92:931-44.

72. Ando Y, Nakazawa T, Oka K, Nakahori K, Kamada T. Cc.snf5, a gene encoding a putative component of the SWI/SNF chromatin remodeling complex, is essential for sexual development in the agaricomycete Coprinopsis cinerea. Fungal Genet Biol. 2013;50:82-9.

73. Nakazawa T, Ando Y, Hata T, Nakahori K. A mutation in the Cc.arp9 gene encoding a putative actin-related protein causes defects in fruiting initiation and asexual development in the agaricomycete Coprinopsis cinerea. Curr Genet. 2016;62:565-74.

74. Ahmed YL, Gerke J, Park HS, Bayram Ö, Neumann P, Ni M, et al. The velvet family of fungal regulators contains a DNA-binding domain structurally similar to NF-kB. PLoS Biol. 2013;11:e1001750.

75. Beyhan S, Gutierrez M, Voorhies M, Sil A. A temperature-responsive network links cell shape and virulence traits in a primary fungal pathogen. PLoS Biol. 2013;11:e1001614.

76. Roberts RG. The velvet underground emerges. PLoS Biol. 2013;11:e1001751.

77. Warner MH, Roinick KL, Arndt KM. Rtf1 is a multifunctional component of the Paf1 complex that regulates gene expression by directing cotranscriptional histone modification. Mol Cell Biol. 2007;27:6103-15.

78. Sarikaya-Bayram Ö, Palmer JM, Keller N, Braus GH, Bayram Ö. One Juliet and four Romeos: VeA and its methyltransferases. Front Microbiol. 2015;6:1.

79. Engh I, Nowrousian M, Kück U. Sordaria macrospora, a model organism to study fungal cellular development. Eur J Cell Biol. 2010;89:864-72.

80. Pöggeler $S$, Nowrousian M, Kück U. Fruiting-body development in ascomycetes. In: Kües U, Fischer R, editors. The Mycota I. Berlin, Heidelberg: Springer; 2006. p. 325-55.

81. Umeda M, Tsunekawa C, Senmatsu S, Asada R, Abe T, Ohta K, et al. Histone chaperone Asf1 is required for the establishment of repressive chromatin in Schizosaccharomyces pombe fbp 1 gene repression. Mol Cell Biol. 2018;18: e00194-18.

82. Adkins MW, Howar S, Tyler JK. Chromatin disassembly mediated by the histone chaperone Asf1 is essential for transcriptional activation of the yeast PHO5 and PHO8 genes. Mol Cell. 2004;14:657-66.

83. Korber P, Barbaric S, Luckenbach T, Schmid A, Schermer UJ, Blaschke D, et al. The histone chaperone Asf1 increases the rate of histone eviction at the yeast PHO5 and PHO8 promoters. J Biol Chem. 2006;281:5539-45.

84. Schermer UJ, Korber P, Hörz W. Histones are incorporated in trans during reassembly of the yeast PHO5 promoter. Mol Cell. 2005;19:279-85.

85. Schwabish MA, Struhl K. Asf1 mediates histon eviction and deposition during elongation by RNA polymerase II. Mol Cell. 2006;22:415-22.

86. Driscoll $R$, Hudson A, Jackson SP. Yeast Rtt109 promotes genome stability by acetylating histone $\mathrm{H} 3$ on lysine 56. Science. 2007;315:649-52.

87. Tsubota T, Berndsen CE, Erkmann JA, Smith CL, Yang L, Freitas MA, et al. Histone H3-K56 acetylation is catalyzed by histone chaperone-dependent complexes. Mol Cell. 2007;25:703-12.

88. Freitag M. Histone methylation by SET domain proteins in fungi. Annu Rev Microbiol. 2017. https://doi.org/10.1146/annurev-micro-102215-095757.
89. Cheloufi S, Elling U, Hopfgartner B, Jung YL, Murn J, Ninova M, et al. The histone chaperone CAF-1 safeguards somatic cell identity. Nature. 2015;528:218-24.

90. Ishiuchi T, Enriquez-Gasca R, Mizutani E, Bošković A, Ziegler-Birling C, Rodriguez-Terrones $\mathrm{D}$, et al. Early embryonic-like cells are induced by downregulating replication-dependent chromatin assembly. Nat Struct Mol Biol. 2015;22:662-71.

91. Borkovich KA, Alex LA, Yarden O, Freitag M, Turner GE, Read ND, et al. Lessons from the genome sequence of Neurospora crassa: tracing the path from genomic blueprint to multicellular organism. Microbiol Mol Biol Rev. 2004:68:1-108.

92. Ballario P, Talora C, Galli D, Linden H, Macino G. Roles in dimerization and blue light photoresponse of the PAS and LOV domains of Neurospora crassa white collar proteins. Mol Microbiol. 1998:29:719-29.

93. Dunlap JC, Loros JJ. Making time: conservation of biological clocks from fungi to animals. Microbiol Spectr. 2017;5. https://doi.org/10.1128/ microbiolspec.FUNK-0039-2016.

94. Michielse CB, Pfannmüller A, Macios M, Rengers P, Dzikowska A, Tudzynski B. The interplay between the GATA transcription factors AreA, the global nitrogen regulator and AreB in Fusarium fujikuroi. Mol Microbiol. 2014;91:472-93.

95. Marzluf $G A$. Genetic regulation of nitrogen metabolism in the fungi. Microbiol Mol Biol Rev. 1997;61:17-32.

96. Feng B, Haas H, Marzluf GA. ASD4, a new GATA factor of Neurospora crassa, displays sequence-specific DNA binding and functions in ascus and ascospore development. Biochemistry. 2000;39:11065-73.

97. Boyes J, Omichinski J, Clark D, Pikaart M, Felsenfeld G. Perturbation of nucleosome structure by the erythroid transcription factor GATA-1. J Mol Biol. 1998;279:529-44.

98. Scazzocchio C. The fungal GATA factors. Curr Opin Microbiol. 2000;3:126-31.

99. Muro-Pastor MI, Gonzalez R, Strauss J, Narendja F, Scazzocchio C. The GATA factor AreA is essential for chromatin remodelling in a eukaryotic bidirectional promoter. EMBO J. 1999;18:1584-97.

100. Grimaldi B, Coiro P, Filetici P, Berge E, Dobosy JR, Freitag M, et al. The Neurospora crassa white Collar-1 dependent blue light response requires acetylation of histone H3 lysine 14 by NGF-1. Mol Biol Cell. 2006;17:4576-83.

101. Brenna A, Grimaldi B, Filetici P, Ballario P. Physical association of the WC-1 photoreceptor and the histone acetyltransferase NGF-1 is required for blue light signal transduction in Neurospora crassa. Mol Biol Cell. 2012;23:3863-72.

102. Hedtke M, Rauscher S, Röhrig J, Rodríguez-Romero J, Yu Z, Fischer R. Lightdependent gene activation in Aspergillus nidulans is strictly dependent on phytochrome and involves the interplay of phytochrome and white collarregulated histone H3 acetylation. Mol Microbiol. 2015;97:733-45.

103. Zaret KS, Mango SE. Pioneer transcription factors, chromatin dynamics, and cell fate control. Curr Opin Genet Dev. 2016;37:76-81.

104. Kamerewerd J, Jansson M, Nowrousian M, Pöggeler S, Kück U. Three alpha subunits of heterotrimeric $\mathrm{G}$ proteins and an adenylyl cyclase have distinct roles in fruiting body development in the homothallic fungus Sordaria macrospora. Genetics. 2008;180:191-206.

105. Hall RA, De Sordi L, Maccallum DM, Topal H, Eaton R, Bloor JW, et al. CO acts as a signalling molecule in populations of the fungal pathogen Candida albicans. PLoS Pathog. 2010;6:e1001193.

106. Klengel T, Liang WJ, Chaloupka J, Ruoff C, Schröppel K, Naglik JR, et al. Fungal adenylyl cyclase integrates $\mathrm{CO} 2$ sensing with CAMP signaling and virulence. Curr Biol. 2005;15:2021-6.

107. Bahn YS, Cox GM, Perfect JR, Heitman J. Carbonic anhydrase and $\mathrm{CO}_{2}$ sensing during Cryptococcus neoformans growth, differentiation, and virulence. Curr Biol. 2005;15:2013-20.

108. Teichert I, Lutomski M, Märker R, Nowrousian M, Kück U. New insights from an old mutant: SPADIX4 governs fruiting body development but not hyphal fusion in Sordaria macrospora. Mol Gen Genomics. 2017:292:93-104.

109. Esser K. Cryptogams - Cyanobacteria, Algae, Fungi, Lichens. London: Cambridge University Press; 1982.

110. Nowrousian M, Cebula P. The gene for a lectin-like protein is transcriptionally activated during sexual development, but is not essential for fruiting body formation in the filamentous fungus Sordaria macrospora. BMC Microbiol. 2005;5:64.

111. Nowrousian M, Masloff S, Pöggeler S, Kück U. Cell differentiation during sexual development of the fungus Sordaria macrospora requires ATP citrate lyase activity. Mol Cell Biol. 1999;19:450-60.

112. Esser K, Straub J. Genetische Untersuchungen an Sordaria macrospora Auersw., Kompensation und Induktion bei genbedingten Entwicklungsdefekten. Z Vererbungsl. 1958;98:729-46. 
113. Klix V, Nowrousian M, Ringelberg C, Loros JJ, Dunlap JC, Pöggeler S. Functional characterization of MAT1-1-specific mating-type genes in the homothallic ascomycete Sordaria macrospora provides new insights into essential and non-essential sexual regulators. Eukaryot Cell. 2010;9:894-905.

114. Bayram Ö, Krappmann S, Ni M, Bok JW, Helmstaedt K, Valerius O, et al. VelB/ VeA/LaeA complex coordinates light signal with fungal development and secondary metabolism. Science. 2008;320(5882):1504-6

115. Bloemendal S, Bernhards Y, Bartho K, Dettmann A, Voigt O, Teichert I, et al. A homolog of the human STRIPAK complex controls sexual development in fungi. Mol Microbiol. 2012;84:310-23.

116. Pöggeler S, Kück U. Highly efficient generation of signal transduction knockout mutants using a fungal strain deficient in the mammalian ku70 ortholog. Gene. 2006;378:1-10.

117. Engh I, Würtz C, Witzel-Schlömp K, Zhang HY, Hoff B, Nowrousian M, et al. The WW domain protein PRO40 is required for fungal fertility and associates with Woronin bodies. Eukaryot Cell. 2007;6:831-43.

118. Nowrousian M, Frank S, Koers S, Strauch P, Weitner T, Ringelberg C, et al. The novel ER membrane protein PRO41 is essential for sexual development in the filamentous fungus Sordaria macrospora. Mol Microbiol. 2007;64:923-37.

119. Yarden O, Plamann M, Ebbole D, Yanofsky C. cot-1, a gene required for hyphal elongation in Neurospora crassa encodes a protein kinase. EMBO J. 1992:11:2159-66.

120. Nowrousian M, Ringelberg C, Dunlap JC, Loros JJ, Kück U. Cross-species microarray hybridization to identify developmentally regulated genes in the filamentous fungus Sordaria macrospora. Mol Gen Genomics. 2005;273:137-49.

121. Ramakers C, Ruijter JM, Lekanne Deprez RH, Moorman AFM. Assumptionfree analysis of quantitative real-time polymerase chain (PCR) data. Neurosci Lett. 2003;339:62-6.

122. Pfaffl MW. A new mathematical model for relative quantification in real-time RT-PCR. Nucleic Acids Res. 2001;29:e45.

123. Pfaffl MW, Horgan GW, Dempfle L. Relative expression software tool (REST) for group-wise comparison and statistical analysis of relative expression results in real-time PCR. Nucleic Acids Res. 2002;30:e36.

124. Nowrousian M, Stajich JE, Chu M, Engh I, Espagne E, Halliday K, et al. De novo assembly of a $40 \mathrm{Mb}$ eukaryotic genome from short sequence reads: Sordaria macrospora, a model organism for fungal morphogenesis. PLoS Genet. 2010;6:e1000891.

125. Trapnell C, Williams BA, Pertea G, Mortazavi A, Kwan G, van Baren MJ, et al. Transcript assembly and quantification by RNA-Seq reveals unannotated transcripts and isoform switching during cell differentiation. Nat Biotech. 2010;28(5):511-5.

126. Zhang Z, López-Giráldez F, Townsend JP. LOX: inferring level of eXpression from diverse methods of census sequencing. Bioinf. 2010;26:1918-9.

127. Love Ml, Huber W, Anders S. Moderated estimation of fold change and dispersion for RNA-seq data with DESeq2. Genome Biol. 2014;15:550.

128. Langmead B, Salzberg SL. Fast gapped-read alignment with bowtie 2. Nat Methods. 2012;9:357-9.

129. Quinlan AR, Hall IM. BEDTools: a flexible suite of utilities for comparing genomic features. Bioinformatics. 2010;26:841-2.

130. Chen W, Liu Y, Zhu S, Green CD, Wei G, Han JD. Improved nucleosomepositioning algorithm iNPS for accurate nucleosome positioning from sequencing data. Nat Commun. 2014;5:4909.

131. Stajich JE, Block D, Boulez K, Brenner SE, Chervitz SA, Dagdigian C, et al. The Bioperl toolkit: Perl modules for the life sciences. Genome Res. 2002;12(10): $1611-8$.

132. Bolger AM, Lohse M, Usadel B. Trimmomatic: a flexible trimmer for Illumina sequence data. Bioinf. 2014;30:2114-20.

133. Krueger F, Andrews SR. Bismark: a flexible aligner and methylation caller for bisulfite-Seq applications. Bioinf. 2011;27:1571-2.

\section{Ready to submit your research? Choose BMC and benefit from:}

- fast, convenient online submission

- thorough peer review by experienced researchers in your field

- rapid publication on acceptance

- support for research data, including large and complex data types

- gold Open Access which fosters wider collaboration and increased citations

- maximum visibility for your research: over $100 \mathrm{M}$ website views per year

At BMC, research is always in progress.

Learn more biomedcentral.com/submissions 